\title{
A composite sandwich plate with a novel core design
}

\author{
Anil Uzal ${ }^{\mathrm{a}}$ Fazil O. Sonmez ${ }^{\mathrm{a}}$ Fatih E. Oz ${ }^{\mathrm{a}}$ Kenan Cinar ${ }^{\mathrm{ab}}$ Nuri Ersoy ${ }^{\mathrm{a}}$ \\ aDepartment of Mechanical Engineering, Bogazici University, Istanbul, Bebek 34342, Turkey

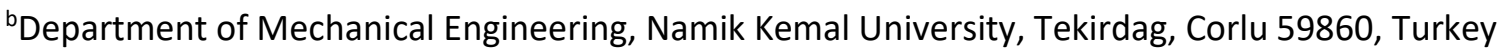

\begin{abstract}
In this study, a new core design is introduced for sandwich composite structures. Its strength and failure behavior are investigated via three-point bending tests. E-glass-fiber-reinforced epoxy resin is selected as the material for both the core and the face sheets. The core has an egg-crate shape. Acoustic emission $(A E)$ method is used to detect the progression of damage. Signals due to elastic waves caused by activated damage mechanisms are investigated in order to identify the corresponding failure modes. A finite element model of the sandwich structure is developed to predict the failure behavior of the specimens under the loading conditions in the tests. A promising agreement between the results of the finite element model and the experiments is observed. The force-deflection-relation, the failure load as well as the region where damage initiates are accurately predicted.
\end{abstract}

Keywords: Sandwich panels, Composite materials, Acoustic emission, Out-of-plane loading, Threepoint bending, Finite element modeling

\section{Introduction}

For engineering applications, achieving an effective structural design is one of the major goals of the design stage. Load-carrying structures are desired to be as light as possible and damage tolerant with high stiffness and strength properties. In some cases, the desired properties may be achieved by using monolithic composites while for some other applications, combining two different types of materials into one discrete structure like hybrid and sandwich composites leads to improved properties in terms of cost and weight. Sandwich structures are usually preferred for weight-critical applications requiring high flexural stiffness and strength. Face sheets are usually made of continuous fiber-reinforced composites or metals to impart high stiffness and strength, whereas core is a lightweight structure, which can be honeycomb, foam, corrugated plate, or truss structure. Separation of skins by placing a core in-between increases the moment of inertia, which increases stiffness and reduces stresses. Each core structure possesses different mechanical and physical characteristics, which make them suitable for different types of application.

Stiffness and strength are the most important properties of sandwich structures that should be considered in design together with weight and cost. Researchers used experimental [1], [2], [3], [4], [5], [6], [7], [8], [9], [10], [11], [12], [13], [14], [15], [16], [17], [18], [19], [20], [21], [22], [23], [24], [25], [26], [27], [28], [29], numerical [1], [2], [5], [10], [14], [16], [17], [19], [20], [21], [23], [24], [27], [28], [29], [30], [31], [32], [33], [34], [35], [36], and analytical [2], [3], [7], [14], [15], [16], [18], [19], [20], [22], [23], [24], [25], [26], [28], [31], [32], [33], [34], [35], [36], [37], [38], [39] methods to investigate mechanical response and failure behavior of sandwich plates with honeycomb [5], [6], [7], [10], [12], [15], [16], [17], [19], [25], [30], [33], [34], [35], corrugated [1], [27], [29], foam [1], [2], [7], [8], [9], [11], [13], [17], [21], [22], [23], [26], [27], [28], [30], [36], [38], truss [3], [18], [24], [39], and web [27], [31] cores under static [2], [3], [4], [5], [6], [7], [8], [9], [10], [11], [12], [13], [14], [15], [16], [17], [18], [19], [20], [21], [22], [23], [24], [25], [26], [27] and dynamic [5], [12], [14], [30], [34] 
loads. Several failure modes were investigated by the researchers including core crushing [5], [6], [10], [12], [17], [25], [19], [24], [25], [27], [28], [35], [39], delamination [4], [8], [18], yielding or fracture of face sheets [3], [7], [12], [25], [26], [28], face wrinkling [3], [7], [12], [20], [22], [24], [38], buckling [4], [11], [18], [24], [25], [27], [32], [33], [37], [39], indentation [2], [3], [7], [9], [10], [12], [14], [15], [16], [21], [22], [23], [34], [37], [38], face sheet-core debonding [4], [11], [27], [32], [36], and core shear failure [3], [7], [8], [12], [13], [14], [15], [18], [19], [22], [24], [26], [27], [28], [35], [38], [39]. In order to investigate different failure modes, different loading conditions are applied in the experiments and the simulations. For this purpose, three-point bending tests [1], [3], [4], [7], [8], [9], [12], [13], [14], [15], [16], [21], [22], [25], [26], [27], [36], [38], [39], four-point bending tests [7], [20], [28], [31], [38], in-plane compression tests [4], [5], [6], [7], [11], [24], [27], [29], [32], [33], flatwise compression tests [4], [10], [17], [19], [27], and indentation tests [2], [3], [7], [9], [10], [12], [14], [15], [21], [22], [23], [34], [37], [38] are conducted. Some researchers [13], [15], [20], [22], [25], [28], [30], [34], [39] proposed methods to predict failure and its mode. Overall, the core material should have sufficient stiffness to prevent local buckling and sufficient strength not to sustain damage. Lateral loads will create shear effects and core has to withstand out-of-plane shear loads without the help of face sheets. Mohamed et al. [27] investigated the flexural behavior of sandwich structures made of glass-fiber reinforced face sheets and foam core reinforced with glass fiber mats. They developed a non-linear FE model to simulate the behavior of the structure under three-point bending. Face sheets are modeled by linear elastic shell elements and foam is modeled by solid elements with non-linear material response. Load carrying capacity of the plates with corrugated core was found to be higher compared to the web-core plates. Manalo et al. [28] studied the flexural behavior of foam-core sandwich structures under four-point bending. They developed a finite element model of the structure using solid elements considering nonlinear material behavior of the core and large displacements. In their model, they included failure criteria for the face sheets and the core.

Load-displacement curves of tested specimens may give some clues regarding the activated failure modes. In addition to examining the changes in the stiffness of specimens, a number of researchers also studied acoustic emission signals arising due to damage taking place in the composite material during loading in order to identify the activated failure modes [40], [41], [42], [43], [44], [45], [46], [47], [48], [49], [50], [51], [52]. The majority of these researchers focused on the peak amplitude and frequency parameters. In 1978, Wadim [40] managed to correlate different ranges of amplitude parameter with different failure mechanisms. According to Wadim, matrix cracking was responsible for elastic waves with lower levels of amplitude, while waves with high amplitudes were generated by delamination and fiber failure. Aramugam et al. [41] found that peak frequency ranges 90$110 \mathrm{kHz}$ and $130-200 \mathrm{kHz}$ were related to matrix cracking and delamination, respectively, for glassepoxy laminates, while the range between 230 and $250 \mathrm{kHz}$ was a sign of debonding; a higher frequency content was observed during fiber failures. Bussiba et al. [43] considered rate of counts and cumulative counts to identify failure modes. Asokan et al. [44] claimed that evaluating acoustic emission (AE) data according to amplitude and duration parameters might help to identify failure modes. Fotouhi et al. [46] performed three-point bending tests on glass/epoxy specimens. They correlated frequency ranges of 100-190, 200-320 and 355-450 kHz to matrix cracking, fiber-matrix debonding, and fiber breakage, respectively. Gutkin et al. [48] conducted various tests on carbonfiber-reinforced polymer specimens including tension, double cantilever beam, and four-point bending tests. They correlated peak frequencies in $0-50 \mathrm{kHz}, 50-150 \mathrm{kHz}$, and $400-500 \mathrm{kHz}$ ranges with matrix cracking, delamination, and fiber breakage, respectively. Li et al. [50] conducted tension tests on woven glass-fiber reinforced epoxy composites with AE monitoring. They correlated lowamplitude and low-frequency signals with transverse matrix cracks in $90^{\circ}$-layers and high-amplitude 
and low-frequency signals with delaminations. In different studies, different frequency and amplitude ranges are associated with certain failure modes; but the generally held view is that high amplitude and frequency signals are generated by fiber breaks, whereas low amplitude and frequency signals are due to matrix damage modes. However, there are also conflicting findings. $\mathrm{Oz}$ et al. [52] reported that high frequency signals might also be associated with transverse cracks.

In this study, a new core design is introduced. The core consists of unit cells having a truncated pyramidal shape with a square base as depicted in Fig. 1. It is similar to an egg crate. It is composed of fiber-reinforced composite layers like the skins. Thickness and orientation of the layers, the size of the unit cell, the core thickness, and the wall angle define the geometric features of the core. It is possible to obtain numerous geometrical configurations by changing these parameters. One may optimize the geometric features for different loading conditions. The space may also be filled with foam to improve some physical properties for specific applications. Although this type of sandwich structure is more costly compared to honeycomb and foam core sandwiches, it is expected to show superior performance in the presence of transverse concentrated or distributed loads and shear loading. Unlike honeycomb cores, it can resist out-of-plane shear forces thanks to the angulated side faces and large contact surfaces. As opposed to corrugated ones, it provides high bending stiffness and strength in the two in-plane directions not only in one direction.

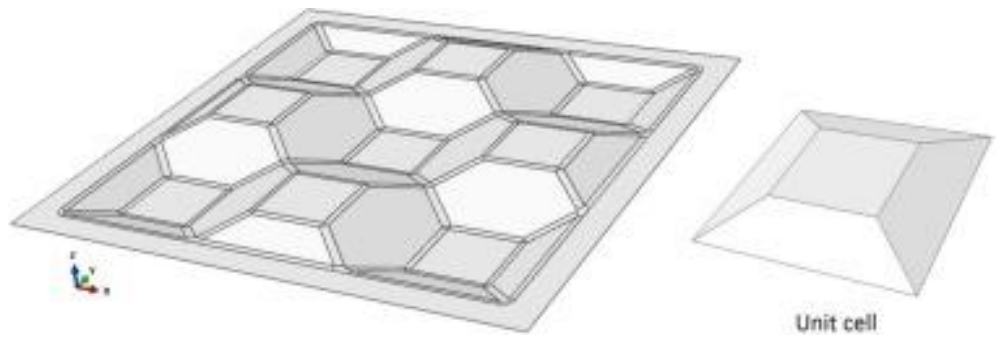

Fig. 1. The schematic representation of the core design introduced in this study and unit cell.

The objective of this study is to investigate the strength and failure behavior of the sandwich plate with the egg-crate shaped core under out-of-plane loading conditions by carrying out three-point bending tests and simulating the test by developing a finite element model to predict its mechanical response under loading.

\section{Preparation of specimens}

\subsection{Material}

In this study, E-glass fiber is chosen as the reinforcement material and epoxy is chosen as the resin material. L285 laminating resin is used with $\mathrm{H} 285$ hardener, both supplied by Hexion, to make the epoxy resin ready for impregnation. The form of the reinforcement material is non-crimp fabric (NCF). From the measurements of the weight and the dimensions of the dry reinforcement and the specimens, the volumetric fractions are calculated. The material properties of the epoxy resin are obtained from the manufacturer (Table 1). The properties of E-glass are obtained from the literature (Table 2).

Table 1. The material properties of the hardened resin [54].

\begin{tabular}{|l|l|}
\hline Tensile strength, Syt (MPa) & $70-80$ \\
\hline Compressive strength, Syc (MPa) & $120-140$ \\
\hline Elastic modulus, Em (GPa) & 3.2 \\
\hline Poisson's ratio, vm & 0.36 \\
\hline
\end{tabular}


Table 2. The material properties of the fiber. [56]

\begin{tabular}{|l|l|}
\hline Elastic modulus, Ef1 (GPa) & 72.4 \\
\hline Poisson's ratio, vf & 0.22 \\
\hline Shear modulus, Gf (GPa) & 26.2 \\
\hline
\end{tabular}

\subsection{Manufacturing of sandwich panels}

Sandwich composite specimens used in the tests are produced by vacuum infusion process (VIP). Both the core and the face sheets of the sandwich structure are composite laminates themselves. A properly cleaned thick glass is used to manufacture two face sheets and a three dimensional mold is used for the core. The mold shown in Fig. 2 is made of RenShape ${ }^{\circledR}$ modeling board. Separately consolidated core and face sheets are bonded to each other by applying ARALDITE ${ }^{\circledR} 2000+$ adhesive. They are held under press for at least $12 \mathrm{~h}$ in order to obtain high bonding quality.

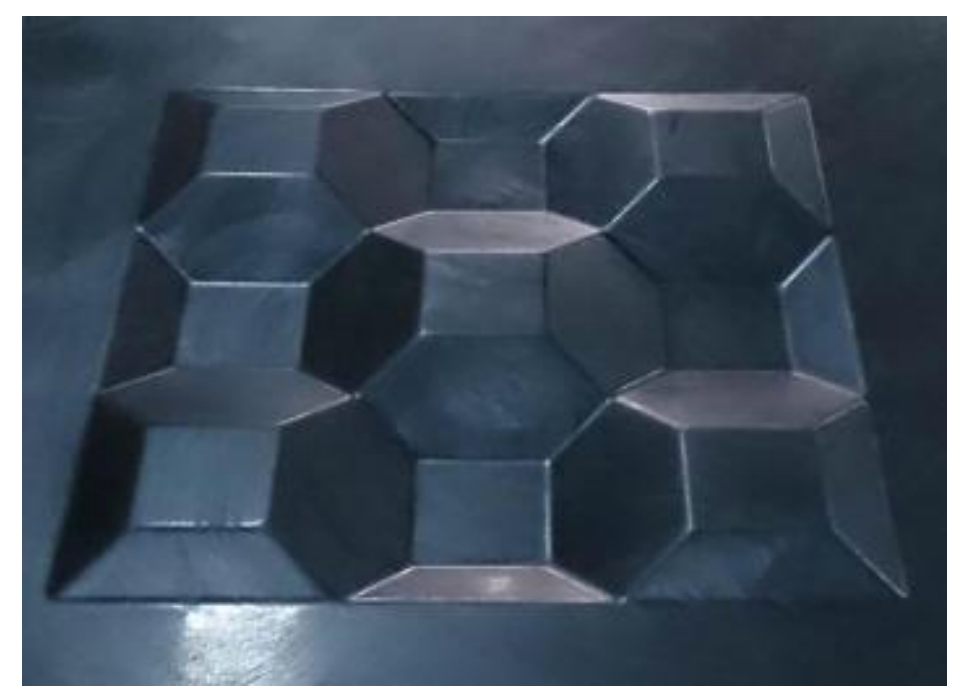

Fig. 2. The lacquer coated mold for the core.

\subsection{Preparation of tension specimens}

The manufacturer of NCF fabrics, Metyx, provides biaxial, [0/90] , and quadraxial, [0/45/-45/90], NCF preforms. Accordingly, tension tests are performed on specimens with two different stacking sequences, cross-ply, [0/90]2s, and quasi-isotropic, [0/45/-45/90]s, in order to determine the strength and stiffness properties of the composites made of these fabrics. In the biaxial fabric, $0^{\circ}$ fibers are biased; the weight ratio of $0^{\circ}$ fibers to $90^{\circ}$ fibers is $161 / 142$ [56]. Thickness ratios are accordingly calculated. Specimens are cut from plates manufactured by VIP with the dimensions of $25 \mathrm{~mm}$ in width and $250 \mathrm{~mm}$ in length. Thickness and volume fraction of cross-ply specimens were $1.36 \mathrm{~mm}$ and $49.5 \%$, respectively; the values were $1.2 \mathrm{~mm}$ and $47.8 \%$ for quasi-isotropic specimens.

\subsection{Tension and three-point bending test setups and testing conditions}

ASTM D3039 standard test procedure is followed to determine the in-plane tensile properties of the laminated composite material. The tension tests are performed by applying displacement controlled loading with the rate of $2 \mathrm{~mm} / \mathrm{min}$ using INSTRON 8801 servo-hydraulic testing machine. A proper specimen installation is followed by placement of a clip-on extensometer and acoustic emission (AE) 
transducers using clamps as shown in Fig. 3. The tests are repeated five times for each layup in accordance with ASTM D3039 test procedure.

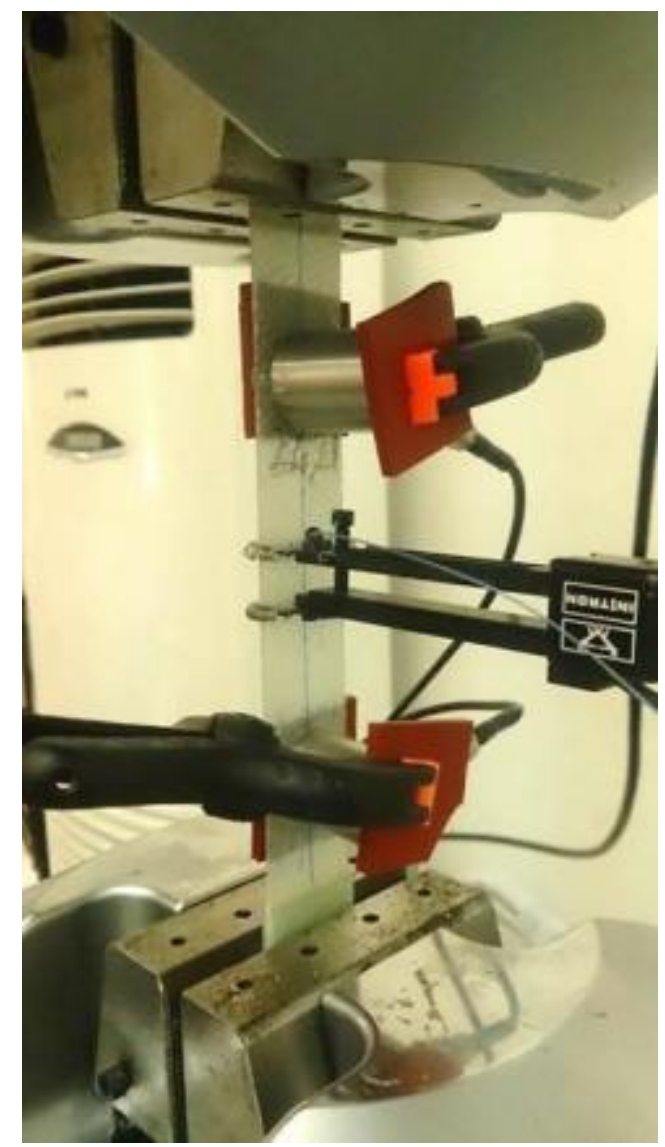

Fig. 3. The tension test setup.

Three sandwich plates are tested using the three-point bending test setup shown in Fig. 4. The core and the face sheets are quasi-isotropic; their stacking sequence is [0/45/-45/90]s. The thicknesses of the core and the face sheets are measured to be $1.40 \mathrm{~mm}$ and $1.20 \mathrm{~mm}$, respectively. Although the same stacking sequence is used for the core and the face sheets, the thickness is different because of the difference in the mold shapes. The three circular bars, used in the fixture, have a length of $300 \mathrm{~mm}$ and a diameter of $26 \mathrm{~mm}$. For specimen 1, both of the AE sensors are placed on the top and no rubber bands are placed between the bars and the specimen. For specimens 2 and 3 , one of the AE sensors is placed on the top and the other is placed on the bottom of the specimen and rubber bands are placed between the bars and the specimen. The test is displacement controlled with the rate of $3.55 \mathrm{~mm} / \mathrm{min}$.

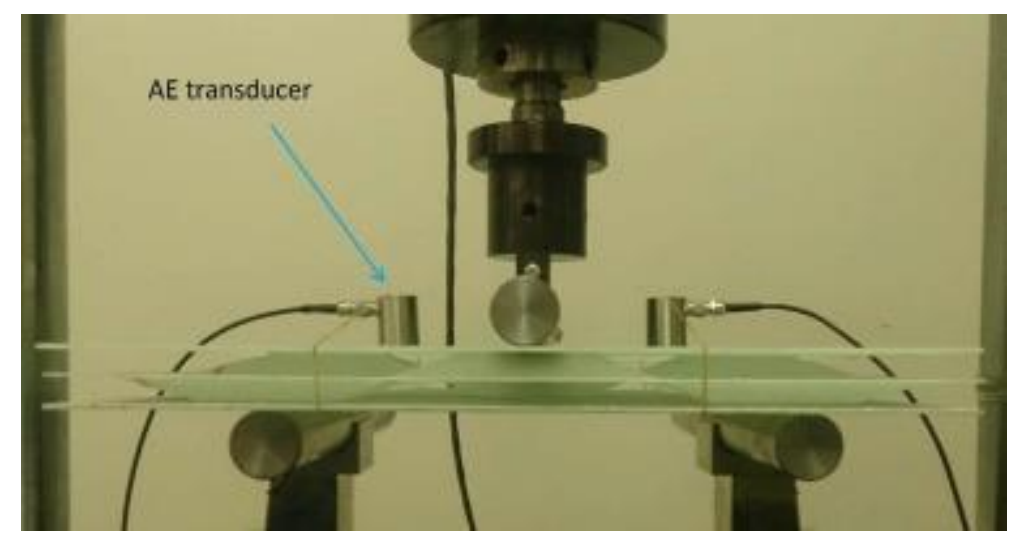


Fig. 4. The three-point-bending test setup.

There are two ASTM standards used to determine the mechanical properties of sandwich plates: ASTM D7249 enables one to determine stiffness and strength of skins with a four-point bending test, whereas ASTM C-393 provides a procedure to obtain the core properties with a three-point bending test. The standard width in ASTM C-393 is $75-\mathrm{mm}$. Considering the dimensions of a unit cell in the egg-crate shaped core, only one row of unit cells could be used, if the standard width were used. In that case, the response of the sandwich plate would not be much different from a corrugated one. For this reason, a non-standard $300 \times 300 \mathrm{~mm}$ square plate with $3 \times 3$ unit cells is used in the tests.

\subsection{Acoustic emission monitoring}

In composite materials, damage initiation usually does not result in a significant change in the macro behavior of composites and it is not easy to determine the first-ply failure experimentally, if the firstply and final failure loads are not same. Acoustic Emission (AE) provides a powerful tool for detecting the first-ply failure, progression of failure, and even the failure mode. Basic failure mechanisms in laminated composite materials are matrix cracking, fiber-matrix debonding, delamination, fiber buckling, and fiber breakage. Each failure mode generates its characteristic AE signal.

In this study, a two-channel MISTRAS AE system is used with PK15I type sensors. Operating frequency range is $100-450 \mathrm{kHz}$ and the resonant frequency is $150 \mathrm{kHz}$. This frequency range is more suitable to detect damage associated with matrix dominated failure modes. PAC AEwinTM software is used for acquisition of $A E$ data. The sampling rate is selected as five mega samples per second. The integrated amplifier is set to $26 \mathrm{~dB}$. Peak definition time, hit definition time, and hit lockout time are selected as 50, 100 and 300 microseconds, respectively. Acoustic emission system produces signals characterized by seven AE features; Amplitude, rise time, counts, duration, energy, absolute energy, signal strength. In addition to these features, an important feature is the peak frequency, which is the frequency of the peak amplitude of a hit.

\section{Tension tests and the analysis of material behavior in the tests}

Strength and stiffness properties of continuous-fiber reinforced composites are typically determined by conducting tests on unidirectional laminates under uniaxial loading like uniaxial tension, pure shear loading. In this way, tensile and compressive strengths in fiber and transverse directions, shear strength, and elastic moduli are obtained. However, since textile composites are multidirectional, this experimental procedure is not applicable. This is also the case for the composite material used in this study, which is epoxy reinforced with non-crimp fabrics. In order to predict the first-ply failure load of the sandwich plate using the FE model, strength and stiffness properties need to be known. In this study, a procedure is proposed to determine these properties using tension test and $\mathrm{AE}$ results for specimens with [0/45/-45/90]s and [0/90]2s layup sequences and a progressive failure model. Using this procedure, longitudinal and transverse tensile strengths, $\mathrm{Xt}$ and $\mathrm{Yt}$, shear strength, $S$, longitudinal and transverse elastic moduli, E1 and E2, and shear modulus, G12, can be obtained.

Continuous-fiber reinforced composites undergo various types of damage under loading. Mode of damage depends on the constituent materials, the lay-up sequence, and the loading conditions. Fig. 5 shows various failure modes observed in [0/45/-45/90]s laminate. These are mainly matrix cracking, delamination, and fiber breakage. Fiber/matrix debonding is also observed. The objective of conducting tension tests in this study is to determine ply-failure load levels. Ply failure may involve different types of damage mechanisms. For example, failure of $90^{\circ}$ plies involves transverse matrix cracks, fiber-matrix debonding, and finally delamination at 45/90 interfaces. Shear failure of $45^{\circ}$ plies involves matrix damage as well as delamination. Oz et al. [52], [53] investigated the damage 
progression in various types of quasi-isotropic laminates during tension tests using AE monitoring, digital image correlation (DIC) and in-situ edge microscopy techniques. According to the findings of these studies, damage initiates in quasi-isotropic laminates in the form of matrix cracks in $90^{\circ}$ plies followed by delamination at $45 / 90$ interfaces. Then, internal cracks develop and delaminations occur in $\pm 45^{\circ}$ plies; finally, fibers in $0^{\circ}$ plies break. Accordingly, ply failures in the quasi-isotropic specimens are also assumed to occur in the same sequence in the present study. As for the specimens with [0/90]2s lay-up sequence, it is well known that $90^{\circ}$ plies fail first, then $0^{\circ}$ plies. In-situ optical observation techniques are not used during the tension tests. Ply-failure load levels are determined considering the changes in the load-displacement diagram as well as the AE signals.

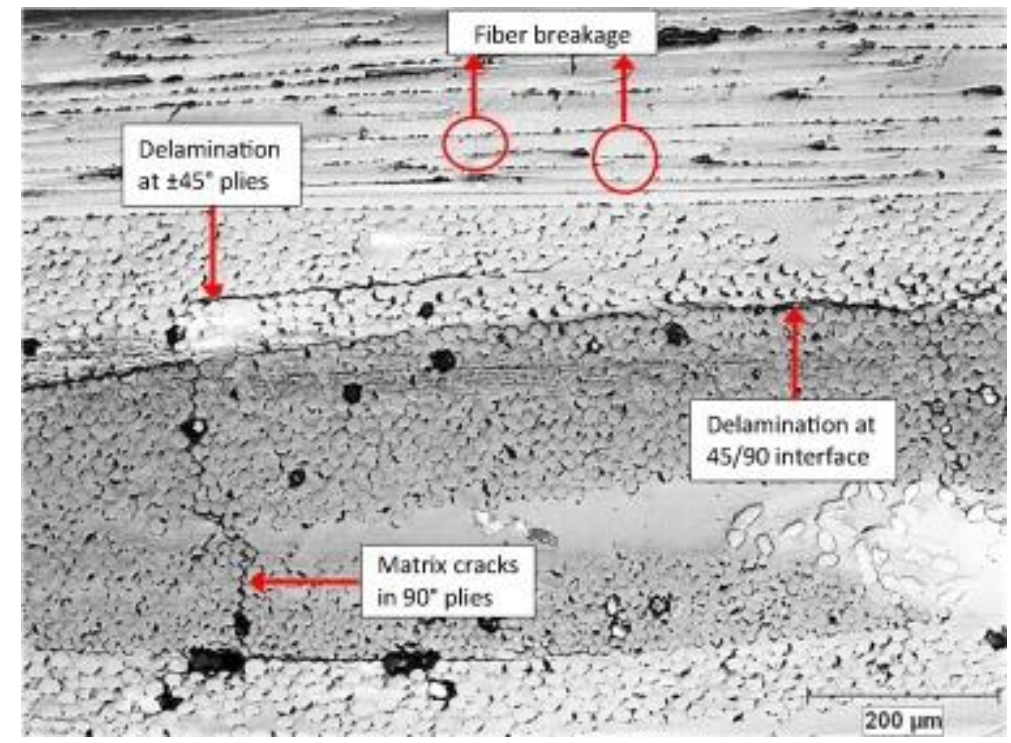

Fig. 5. Damage modes observed in a micrograph of [0/45/-45/90]s laminate.

\subsection{Tension tests}

Fig. 6 shows the peak frequency distribution as well as the energy levels of AE hits for three quasiisotropic specimen, [0/45/-45/90]s, together with the load-strain curve. Energy parameter is the time integral of the absolute signal voltage [57]. High-energy peaks may be associated with damage; but they may also occur due to sliding of transducers and grips over the specimen. Relative magnitude of energy depends on the type and extent of damage as well as the distance between the transducers and the location of damage. Its magnitude also depends on the value of energy reference gain, which is selected as $20 \mathrm{~dB}$. The relative magnitudes of the energy peaks, not the absolute magnitudes, are taken into consideration in the AE analysis; for these reasons, energy values are not shown in the graph, they are just scaled to fit the graph. The graph also includes the cumulative count, which is the total number of $A E$ hits up to a certain time. The shape of the curve, not the value of the cumulative count, is important in interpreting the signal. For this reason, it is also scaled to fit the graph; so all the data can be seen in a single figure. Noise in AE monitoring is an important problem. In order to filter background noise produced by the servo-hydraulic test machine or another source, threshold level for amplitude is adjusted to $45 \mathrm{~dB}$. Still, this does not totally eliminate noise signals. Additionally as a post-processing filtering, only signals consecutively recorded by each sensors with a difference in recording time less than $10 \mathrm{~ms}$ are kept; others are not taken into consideration. This filtering method does not change the general AE distribution, but provides a more clear view of signals associated with damage modes. 

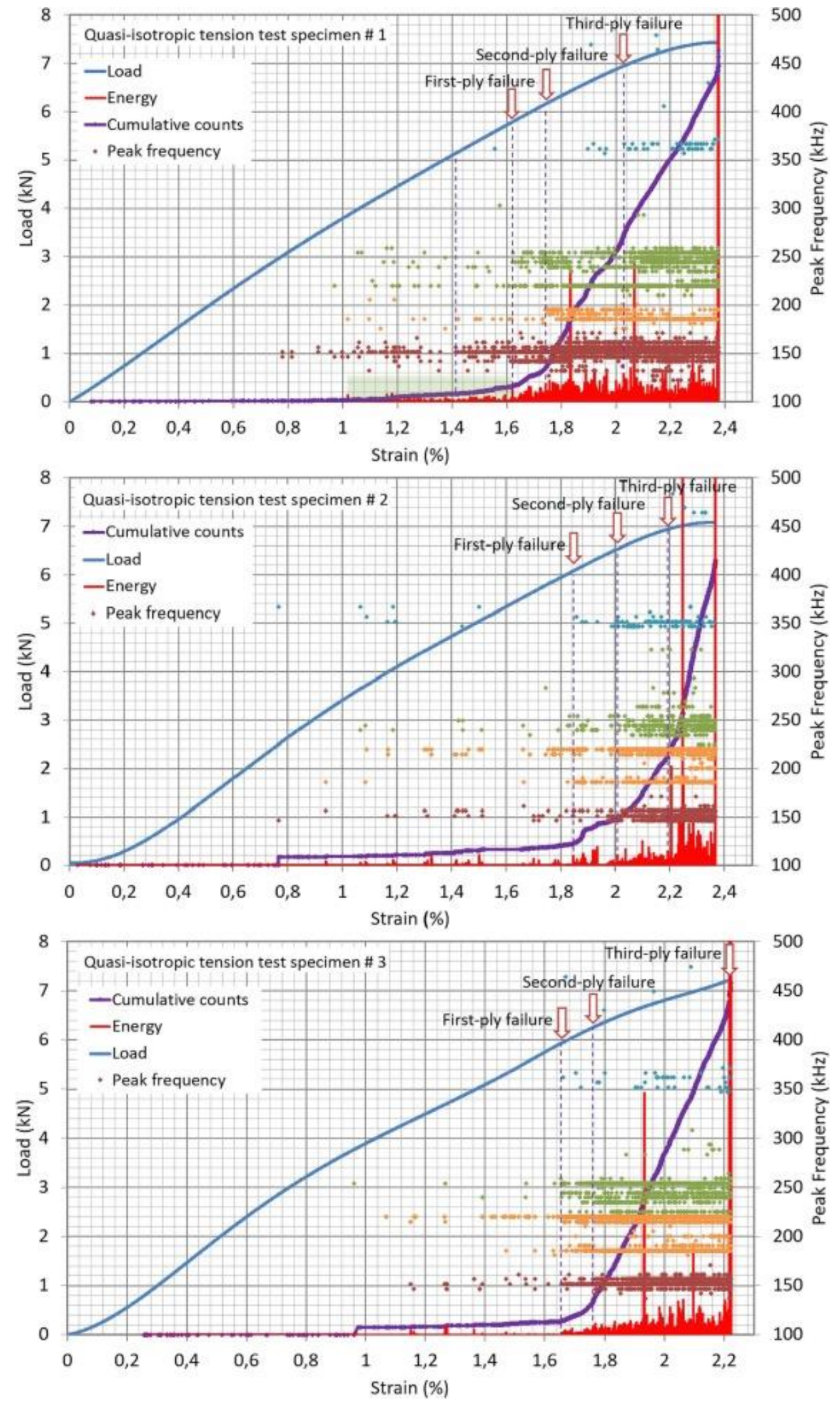

Fig. 6. The peak frequency distribution, the energy levels, and the cumulative counts of the AE hits and the load vs. strain for quasi-isotropic tension test specimens with layup configuration [0/45/45/90]s. 
The specimens do not exhibit an appreciable change in their stiffness until the load reaches about $7 \mathrm{kN}$; then, the specimens suddenly fracture. If one considers only the load-displacement curve, one may get the impression that the specimens fail in an instant without giving any warning until the last stages of loading. However, this is not the case. Evaluation of the AE data together with the loaddisplacement data gives more reliable information on the progression of damage. It is reported that higher dominant frequency values are obtained when more critical damage occurs [41]. One may assume that damage first occurs in the form of transverse matrix cracks in $90^{\circ}$ plies. By observing the peak frequency plots in Fig. 6, one may tentatively conclude that $130-170 \mathrm{kHz}$ band corresponds to matrix cracking; fiber breakage generates signals at much higher frequencies, at about $350-370 \mathrm{kHz}$ band. As seen in the figure, the AE instrument starts to receive signals at about $150 \mathrm{kHz}$ at load levels as low as $3.0 \mathrm{kN}$ for the first specimen. However, these may not be considered a result of total failure of a lamina, because energy levels of these signals are quite low. These are likely to be due to development of micro cracks or local damage. Before load level reaches $5.8 \mathrm{kN}$ in the first specimen, signals are also received in $180-200 \mathrm{kHz}$ band and $220-260 \mathrm{kHz}$ band. Because the density of these signals is low and the energy levels are low, these may not be attributed to ply failure or macro damage; the source of these signals may be micro damage or sliding of extensometer or $\mathrm{AE}$ transducers. It should also be noted that the load-displacement curve is linear up to $3 \mathrm{kN}$; after that the slope continually decreases, i.e. the stiffness gradually degrades. This indicates development and progression of some matrix cracks. However, initial damage in a ply may not be considered as ply failure unless further damage progression is triggered. $5.1 \mathrm{kN}$ is a possible first-ply failure load level for the first specimen, beyond which the number of hits in 140-160 kHz range increases. However, energy levels remain low beyond this load level. Any local damage is not considered as failure unless damage progressively spreads in the layer while the load is increased. Critical matrix failure can be assumed to occur at about $5.80 \mathrm{kN}$ in $90^{\circ}$ plies and this level can be accepted as the first-ply failure load of the first quasi-isotropic specimen, because the $\mathrm{AE}$ signal has a high energy level, the number of hits in 140-160 kHz range significantly increases and consistent hits are obtained in $220-260 \mathrm{kHz}$ band beyond this level. Besides, energy levels of the hits increase henceforth and the curve of the cumulative counts exhibits a considerable increase in slope. These indicate significant damage progression in the $90^{\circ}$ plies. At about $6.2 \mathrm{kN}$ load and $1.76 \%$ strain, AE instrument starts to detect hits within $180-200 \mathrm{kHz}$ band with high density. The energy levels of these signals are higher than the ones before, energy levels of the subsequent signals are also high. A significant change occurs in the slope of the cumulative-counts curve. Accordingly, $6.2 \mathrm{kN}$ is taken to be the second-ply failure load. This is attributed to initiation of failure in $\pm 45^{\circ}$ plies in the form of delamination and matrix cracks. Up to $3.0 \mathrm{kN}$, there is almost no degradation in the stiffness of the specimen; the slope of the load-displacement curve does not change. Between 3.0 and $7.2 \mathrm{kN}$, the degradation is small and gradual. However, when the load exceeds $6.95 \mathrm{kN}$, the rate of decrease in the slope becomes significantly higher. Besides, signals are consistently registered in $350-370 \mathrm{kHz}$ band after this load level is exceeded. Based on these two indications, one may conclude that fiber damage mechanism is activated for the fibers aligned in the tension direction. The third-ply failure is then due to fiber breakage in $0^{\circ}$ plies. Fiber failure quickly degrades the load-carrying capacity of the laminate and soon final failure occurs.

For the second specimen, the first, second, and third-ply failure loads are estimated to be $6.08 \mathrm{kN}$, $6.64 \mathrm{kN}$, and $6.96 \mathrm{kN}$, respectively. For the third specimen, these failure loads are estimated to be $5.94 \mathrm{kN}, 6.25 \mathrm{kN}$, and $7.2 \mathrm{kN}$, respectively. As discussed before, $90^{\circ}$ plies fail first during tension loading of $[0 / 45 /-45 / 90]$ s specimens, then $+45 /-45$ plies, finally $0^{\circ}$ plies. Considering that there are conflicting reports regarding correlation of peak frequencies and amplitudes with damage modes and the fact that ply failures may involve activation of a number of damage mechanisms, these ply- 
failure load levels are determined considering the changes in the slope of load-deflection curve and the changes in AE signal characteristics. As discussed before, common features of the AE signals at these failure load levels are change in the slope of the cumulative-counts curve, increase in the energy levels of the subsequent hits, formation of new frequency bands or increase in the density of the existing frequency bands. For the third specimen, the third-ply failure load is taken the same as the ultimate load level, considering that initiation and progression of fiber damage in $0^{\circ}$ plies would certainly cause a considerable decrease in stiffness, but no significant degradation occurs in the stiffness of the third specimen before the ultimate load level is reached. Two more quasi-isotropic specimens are tested and their load-displacement curves and AE signal characteristics are found to be similar to those shown in Fig. 6.

Another AE parameter that researchers try to relate to damage mechanisms in composites is amplitude of acoustic signals. Fig. 7 shows the amplitude distribution, the cumulative counts as well as the energy levels of the $A E$ hits for a cross-ply specimen, [0/90]2s, together with the load-strain curve. The load at fracture exceeds $10 \mathrm{kN}$. The load carrying capacity of cross-ply specimens is higher under uniaxial loads along the fiber direction in comparison to quasi-isotropic specimens as expected. At strain levels about $0.3 \%$ and $0.47 \%$ corresponding to $2 \mathrm{kN}$ and $3 \mathrm{kN}$ load levels, signals are detected with very high energy levels. Until $2 \mathrm{kN}$, load-strain curve is constant; between $2 \mathrm{kN}$ and $3 \mathrm{kN}$, a slight degradation in stiffness occurs. There is also jump in the cumulative-counts curve. For these reasons, these signals are attributed to damage in the specimen. However, this is not considered as a total lamina failure. This load level is too low to have a matrix failure in $90^{\circ}$ plies and the density of the hits remains low up to $6 \mathrm{kN}$. This damage is believed to arise due to stress concentration from stitches. This test is repeated five times; the same behavior is observed at these load levels in all the specimens. In order to find the source of the signals and the change in the slope of the load-displacement curve, one need to stop the test after $3.0 \mathrm{kN}$ load is exceeded, cut the specimen, and examine micrographs of the sections. When the load exceeds $8.0 \mathrm{kN}$, the transducers start to detect high numbers of AE signals with a high energy peak. Significant increase in the density of registered hits clearly indicates initiation of substantial damage within the laminate, besides a new band of $A E$ hits, $68-80 \mathrm{~dB}$, is activated. The cumulative-counts curve exhibits a jump and a considerable increase in slope. Accordingly, the first-ply failure load level can be taken as $8.0 \mathrm{kN}$. Based on the findings of Asokan et al. [44], and the distribution of AE hits in Fig. 7, 48-68 dB amplitudes can be assumed to indicate weak matrix damage; $68-80 \mathrm{~dB}$ amplitudes with a duration shorter than $300 \mu$ s may indicate strong matrix damage; 68-80 dB amplitudes with a duration longer than $300 \mu$ s may indicate weak delamination together with strong matrix damage; amplitudes higher than $80 \mathrm{~dB}$ with a duration longer than $300 \mu$ s may indicate strong delamination; amplitudes higher than $80 \mathrm{~dB}$ with a duration shorter than $300 \mu$ s may indicate fiber breakage. Accordingly, matrix failure occurs at $8.0 \mathrm{kN}$ in $90^{\circ}$ plies. At $9.5 \mathrm{kN}$, the $A E$ instrument starts to detect hits with amplitudes higher than $80 \mathrm{~dB}$. These are believed to be generated by delaminations at the interface between $0^{\circ}$ plies and $90^{\circ}$ plies. Previous studies [52], [53] showed that $90^{\circ}$ plies failed due to transverse cracks followed by delaminations using in-situ edge microscopy. Transverse matrix cracks in $90^{\circ}$ layers propagate with the increase in load until they reach the interface; then they may trigger delaminations along the interface. The slope of the cumulative-counts curve significantly increases at this point, indicating high volume of subsequent AE signals. The second-ply failure occurs at $9.9 \mathrm{kN}$ due to fiber breakage. There is a considerable change in the slope of the load-displacement curve after this. Besides, $A E$ signals with amplitudes greater than $90 \mathrm{~dB}$ are recorded. The density of the $A E$ signals in the 80-90 dB range increases. Accordingly, fibers in $0^{\circ}$ plies start to fail beyond this level, which soon consumes the load carrying capacity of the laminate. 


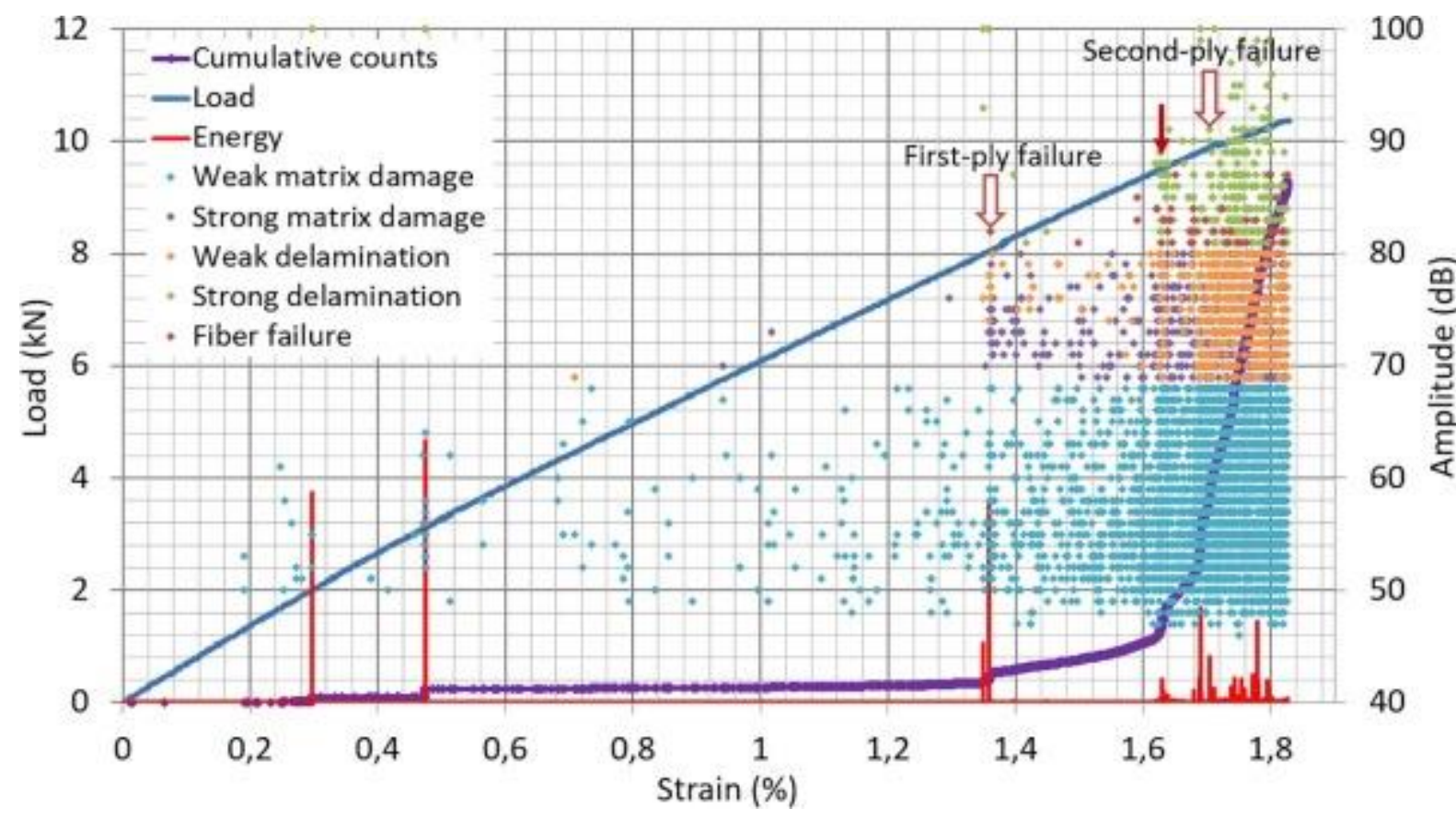

Fig. 7. The amplitude distribution, the energy levels and cumulative counts of the AE hits and the load vs. strain curve for a cross-ply tension test specimen with layup configuration [0/90]2s .

As a summary of the tension test results presented in Fig. 6, Fig. 7, Table 3 gives the ply failure load levels and the corresponding failure modes for [0/45/-45/90]s and [0/90]2s laminates.

Table 3. Failure modes and the corresponding load levels in tension tests.

\begin{tabular}{|l|l|l|l|l|}
\hline $\begin{array}{l}{[0 / 45 /-} \\
45 / 90] s\end{array}$ & 1st ply failure & 2nd ply failure & 3rd ply failure & \\
\hline Failure mode & $\begin{array}{l}\text { Matrix cracks in } 90^{\circ} \\
\text { plies }\end{array}$ & Delamination at $\pm 45^{\circ}$ plies & $\begin{array}{l}\text { Fiber failure at } 0^{\circ} \\
\text { plies }\end{array}$ & \\
\hline Specimen 1 & 5.80 & 6.20 & 6.95 & $\mathrm{kN}$ \\
\hline Specimen 2 & 6.08 & 6.64 & 6.96 & 7.20 \\
\hline Specimen 3 & 5.94 & 6.25 & 3rd ply failure & \\
\hline [0/90]2s & 1 st ply failure & 2nd ply failure & $\begin{array}{l}\text { Fiber failure at } 0^{\circ} \\
\text { plies }\end{array}$ & \\
\hline Failure mode & $\begin{array}{l}\text { Matrix cracks in } 90^{\circ} \\
\text { plies }\end{array}$ & $\begin{array}{l}\text { Delamination at } 0 / 90^{\circ} \\
\text { interface }\end{array}$ & 9.90 & $\mathrm{kN}$ \\
\hline Specimen 1 & 8.00 & 9.50 & &
\end{tabular}

\subsection{Estimation of material properties}

Given the stiffness properties of the resin and reinforcement materials, the stiffness properties of the composite material are found using the rule of mixtures as $\mathrm{E} 1=36.3 \mathrm{GPa}, \mathrm{E} 2=5.9 \mathrm{GPa}$, $\mathrm{G} 12=2.2 \mathrm{GPa}, \mathrm{v12}=0.29$. Considering that although fibers in non-crimp fabrics do not have out-ofplane waviness, but they are curved within the plane and there may be resin rich or starved regions within the composite, one may expect that micromechanics formulations developed for unidirectional laminae overestimate the strength and stiffness properties of composite laminates reinforced by non-crimp fabrics. For these reasons, the values for the stiffness components are optimized to fit the experimental load-strain curves; only the estimated value for $v 12$ is adopted. 
The resulting values for the stiffness properties of E-glass-epoxy unidirectional lamina are listed in Table 4. The elastic modulus is assumed the same in tension and compression.

Table 4. Stiffness properties for unidirectional E-glass-epoxy lamina.

\begin{tabular}{|l|l|}
\hline E1, longitudinal elastic modulus (GPa) & 30.0 \\
\hline E2, transverse elastic modulus (GPa) & 5.0 \\
\hline v12, in-plane Poisson's ratio & 0.29 \\
\hline G12, shear modulus (GPa) & 1.8 \\
\hline
\end{tabular}

In order to obtain the strength properties of unidirectional E-glass reinforced epoxy, a progressive damage model based on the classical lamination theory $(C L T)$ and the maximum stress failure theory is developed that simulates the mechanical behavior of the tension test specimens. Fig. 8 shows a comparison between the experimental load-strain curves of cross-ply and quasi-isotropic tension test specimens and the curves predicted by the progressive model using the stiffness properties given in Table 4. The predicted curves almost coincide with the initial linear portions of the empirical curves. This shows that the values for the stiffness properties of unidirectional lamina given in Table 4 provide a good fit. As discussed before, ply-failure load levels are determined based on the AE data. First-ply failure of the quasi-isotropic specimen with [0/45/-45/90]s layup configuration occurs at $5.8 \mathrm{kN}$ due to matrix failure in $90^{\circ}$ plies. The normal stress transverse to the fibers in the failed layers is $69 \mathrm{MPa}$ according to CLT. Hence, the transverse tensile strength, $\mathrm{Yt}$, is taken to be $69 \mathrm{MPa}$. Above this load level, the matrix dominated stiffness components, E2, v12, v21, and G12, of $90^{\circ}$ plies are degraded by multiplying their values given in Table 4 by a degradation factor, $\mathrm{dm}$; so their subsequent values after damage occurs in $90^{\circ}$ plies are dmE2, dmv12, dmv21, and dmG12. The fibers are assumed intact. The value of $\mathrm{dm}$ is chosen as 0.2 so that the slope of the predicted curve would be about the same as that of the experimental curve at this load level, and the two curves would become closer. The second-ply failure occurs due to shear failure in $45^{\circ}$ plies at $6.2 \mathrm{kN}$. The shear stress in these plies in the principal material coordinates is found to be $40 \mathrm{MPa}$. Accordingly, in-plane shear strength, $\mathrm{S}$, is taken as $40 \mathrm{MPa}$. The matrix dominated stiffness properties, E2 , v12 , $\mathrm{v} 21$, and $\mathrm{G} 12$, of $45^{\circ}$ plies are then degraded by taking the value of the degradation factor, $\mathrm{dm}$, as 0.6. The progressive damage model assumes that ply-failures occur suddenly with total lamina failure; for this reason, the predicted curve is piecewise linear with sudden drops in load level. Actually, total failure of a layer does not occur suddenly; on the contrary, the damage in the specimens occurs progressively as can be seen in Fig. 8; the slope of the load-displacement curve of the tension-test specimen continually decreases beyond the linear range. Gradual decrease in the slope indicates that damage in a layer occurs progressively leading to progressive degradation in stiffness. The model uses the maximum stress theory, which neglects the interaction between intralaminar failure modes. However, the resulting error is assumed tolerable for the purposes of engineering design. Third-ply failure occurs at $6.95 \mathrm{kN}$ due to fiber failure in $0^{\circ}$ plies. Normal stress along the fiber direction in $0^{\circ}$ plies calculated with the degraded stiffness values for $90^{\circ}$ and $45^{\circ}$ plies is $612 \mathrm{MPa}$. Accordingly, the longitudinal tensile strength, $\mathrm{Xt}$, is taken as $612 \mathrm{MPa}$. The same procedure is applied to cross-ply specimens, [0/90]2s. Matrix failure in $90^{\circ}$ plies occurs at $8.0 \mathrm{kN}$, then fiber failure follows at $9.9 \mathrm{kN}$. dm is again taken to be equal to 0.2 after matrix failure. According to these load levels, the transverse tensile strength, $\mathrm{Yt}$, and the longitudinal tensile strength, $\mathrm{Xt}$, are found to be $64 \mathrm{MPa}$ and $532 \mathrm{MPa}$, respectively. These values are about $10 \%$ lower than the ones calculated for the quasi-isotropic specimens. Because quasi-isotropic layup configuration is used in the sandwich plates and the cross-ply tension specimens sustain premature damage, the values of strength parameters calculated for quasi-isotropic tension test specimens are 
adopted in the finite element modeling of the sandwich plates. The above-mentioned procedure is also applied to the other two quasi-isotropic tension-test specimens and their strengths in principal material directions are found. Then, average of the values estimated for the three quasi-isotropic specimens is calculated. As for the compressive strengths, the data reported in the technical data sheet of the resin material [54] are considered. According to the data sheet, the epoxy reinforced with 16 -ply $8 \mathrm{H}$ satin woven glass fabric with $43 \%$ fiber content has a compressive strength about $10 \%$ lower than its tensile strength. Bibo et al. [58] and Laustsen et al. [59] reported the value of compressive strength for epoxy reinforced with non-crimp glass fabrics slightly lower than the tensile strength. Considering also that the compressive strength of the epoxy material is larger than its tensile strength as given in Table 2, longitudinal and transverse compressive strengths of unidirectional glass-epoxy laminate, $\mathrm{Xc}$ and $\mathrm{Yc}$, are taken as $-600 \mathrm{MPa}$ and $-120 \mathrm{MPa}$, respectively. Considering that initial failure of sandwich specimens are observed to occur due to tensile stresses not compressive stresses, tests are not conducted to determine the compressive strengths of the material, instead their values are estimated based on the values reported in the literature. Estimated and calculated strength properties of unidirectional E-glass-epoxy lamina are given in Table 5.

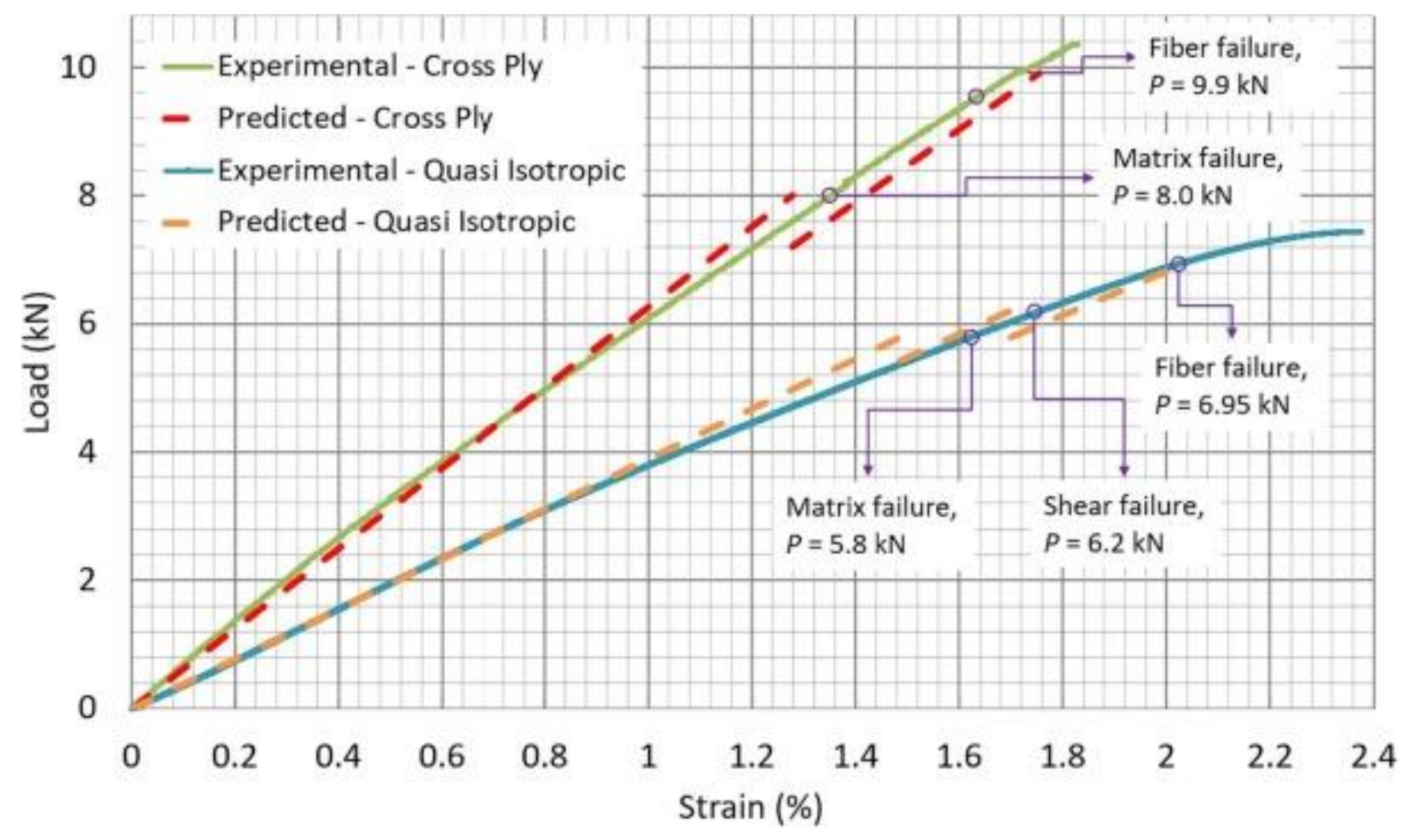

Fig. 8. Experimental load-strain curves of tension test specimens with cross-ply, [0/90]2s, and quasiisotropic, [0/45/-45/90]s, layup configurations and the curves predicted by the progressive damage model.

Table 5. Strength properties for unidirectional E-glass-epoxy lamina.

\begin{tabular}{|l|l|}
\hline $\mathrm{Xt}$, longitudinal tensile strength (MPa) & 619 \\
\hline $\mathrm{Xc}$, longitudinal compressive strength (MPa) & -600 \\
\hline $\mathrm{Yt}$, transverse tensile strength (MPa) & 69 \\
\hline $\mathrm{Yc}$, transverse compressive strength, (MPa) & -120 \\
\hline $\mathrm{S}$, shear strength, (MPa) & 41 \\
\hline
\end{tabular}




\section{Finite element analysis of three-point bending and failure load prediction}

In order to predict the failure load and stiffness of the sandwich structure under three-point bending, an explicit finite element model is developed using ABAQUS finite element software. Explicit method is preferred over the implicit one considering buckling and unstable deformation of the side walls of the core. The solution is iteratively obtained by solving the dynamic equilibrium equation [60]:

(1) $[M]\left\{u^{\prime \prime}\right\}=\{F\}-\{l\}$

where $[\mathrm{M}]$ is the lumped mass matrix, $\left\{\mathrm{u}^{\prime \prime}\right\}$ is the vector of nodal accelerations, $\{\mathrm{F}\}$ is the vector of externally applied forces, $\{1\}$ is the vector of internal forces due to element stresses. The state of the structure at next time steps is obtained from the previous ones using the explicit central difference integration rule [60].

The face sheets and core are modeled separately and assembled together. The boundary conditions of the model reflect the physical loading conditions in three-point bending tests. The predicted region of failure, the deflection at which failure occurs, and the corresponding reaction force are compared with the physical test results in order to validate the model.

The base area of a unit cell of the core structure, which is depicted in Fig. 1, is $100 \mathrm{~mm}$ to $100 \mathrm{~mm}$ and the top area is $50 \mathrm{~mm}$ to $50 \mathrm{~mm}$. In the specimens, nine of these unit cells are placed next to each other to create a $3 \times 3$ core structure. However, before merging these cells into a single part in the CAD model of the specimen, four of them are flipped over. The height of a single cell is $10 \mathrm{~mm}$, which means the core thickness is $20 \mathrm{~mm}$ from top to bottom. After merging, fillets with $5-\mathrm{mm}$ radius of curvature are introduced and an outer frame is added as shown in Fig. 1. Lateral dimensions of the parts (in $x$ and y directions) are $340 \times 340 \mathrm{~mm}$. Shell elements are generated through the surface. Additionally, 3D circular bars are created as rigid parts. A model of 3-mm-thick rubber band is also created between the rigid bars and the face sheets using 3D deformable solid elements.

In the test specimens, the core is attached to the top and bottom faces using an adhesive. Gross debonding between the skins and the core is not observed in the experiments. Partial debonding is not assumed to occur before first-ply intralaminar failure occurs. Accordingly, debonding behavior of the adhesive is not modeled. Deformation in the adhesive layer can be assumed negligibly small compared to the overall deformation of the sandwich plate. For these reasons and because of the difficulties of modeling a very thin layer, the adhesive is not included in the finite element model. The interaction surfaces where adhesive is applied are simply tied to each other. Contact properties between the bars and the part are defined as frictionless for tangential behavior and "hard-contact" for normal behavior.

The rigid bars contacting the bottom of the sandwich plate are fixed by setting all displacement degrees of freedom to zero. The motion of the rigid bar at the top is only allowed in the transverse direction, $z$.

In the face sheets, S4R elements are generated. S8R element type is used in the core part. A mesh convergence study is conducted in order to decide the element size. While applying the same loading conditions, different element sizes are selected. Based on the mesh convergence analysis, the element sizes for the core and sheets are selected as $4 \mathrm{~mm}$ and $5 \mathrm{~mm}$, respectively. Fig. 9 shows the meshed assembly. 


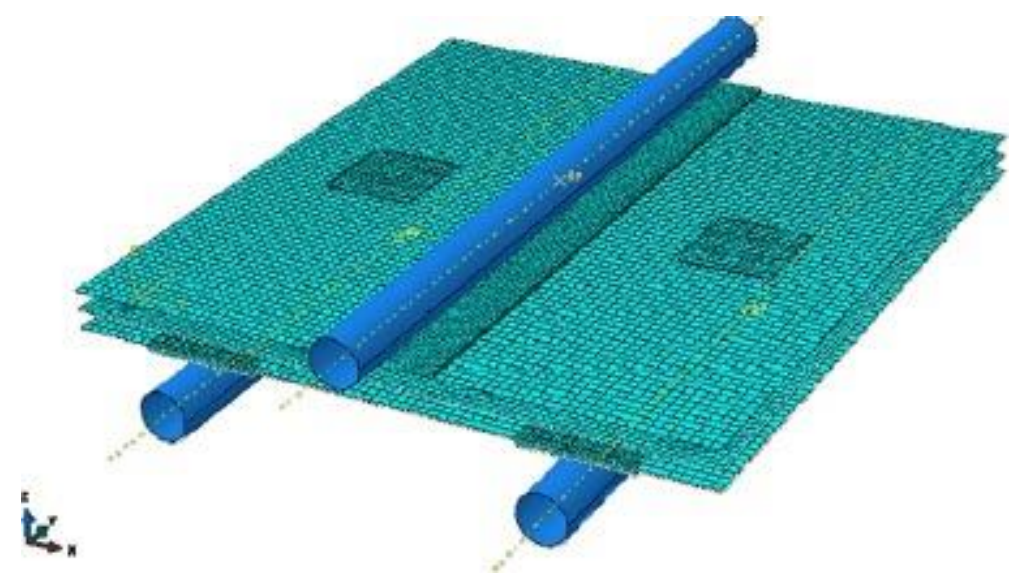

Fig. 9. FE model of three-point bending and meshed assembly.

The mechanical properties given in Table 4, Table 5 are used in the structural and failure analyses of the sandwich plates. The plate is assumed to be composed of individual unidirectional E-glassreinforced epoxy layers even though they are held by stitches. The properties determined by the aforementioned procedure are assumed to reflect the mechanical response of the layers.

CLT enables defining the stress-strain relation and the mechanical behavior of each lamina in terms of mid-surface strains and curvatures of the laminate. In the tension tests, the strain and load data are recorded for the specimens. Thanks to the mid-plane symmetry, the curvature parameters are equal to zero.

The first-ply failure load for the sandwich plate is estimated through an iterative scheme based on the secant algorithm. Tsai-Hill failure model is used to predict whether the plate fails or not for a given displacement of the upper bar. When the failure index is equal to or more than 1.0, the part is assumed to have sustained initial damage. A Python Script code is developed to implement the secant algorithm in order to find the displacement of the upper bar that makes the maximum failure index value equal to 1.0 .

\section{Three-point bending tests of the sandwich plates}

\subsection{Experimental results}

In order to observe the failure behavior of the new sandwich design and verify the finite element model, three sandwich plates are manufactured and tested using a three-point bending test setup.

The tests are planned such that the load is increased until significant damage occurs in the plates. As seen in Fig. 10, the plate keeps its integrity although the deflection at the end of the experiment exceeds almost three times its total thickness. At the peak load, the measured reaction force reaches $4820 \mathrm{~N}$; the corresponding deflection is measured as $5.70 \mathrm{~mm}$. For the other two specimens, the peak loads are measured to be $4430 \mathrm{~N}$ and $4650 \mathrm{~N}$. Because 3-mm-thick rubber bands are placed between the bars and the specimens in the other tests, the corresponding displacements are larger, which are measured as $8.62 \mathrm{~mm}$ and $9.67 \mathrm{~mm}$. Rubber bands are used in the other tests to reduce stress concentration and prevent generation of $A E$ signals due to sliding between the bars and the specimen. It should be noted that characteristics of AE signals obtained in tension tests and threepoint bending tests are different. There are several reasons for this. First, there is a thin adhesive layer between the core and the top and bottom plates. Damage in adhesive layers is a different failure mode. Under three-point bending, compressive stresses also develop, which trigger different 
damage modes. Moreover, attenuation of AE signals is different, because the shape and the size of the specimens are different.

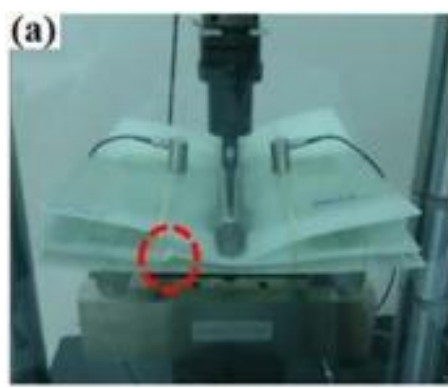

(d)

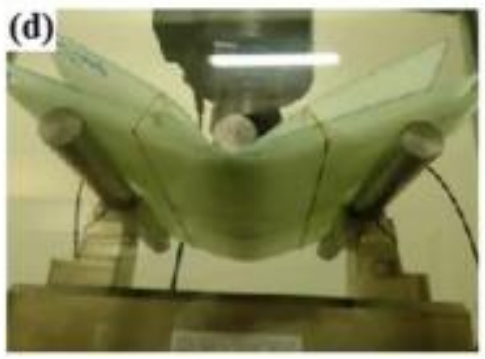

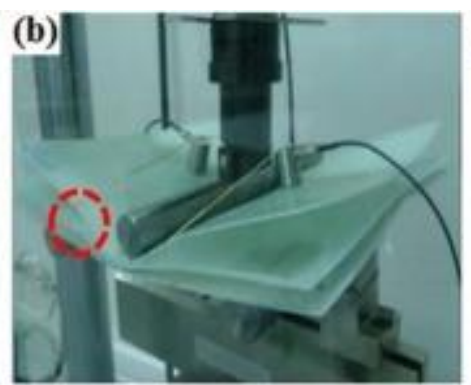
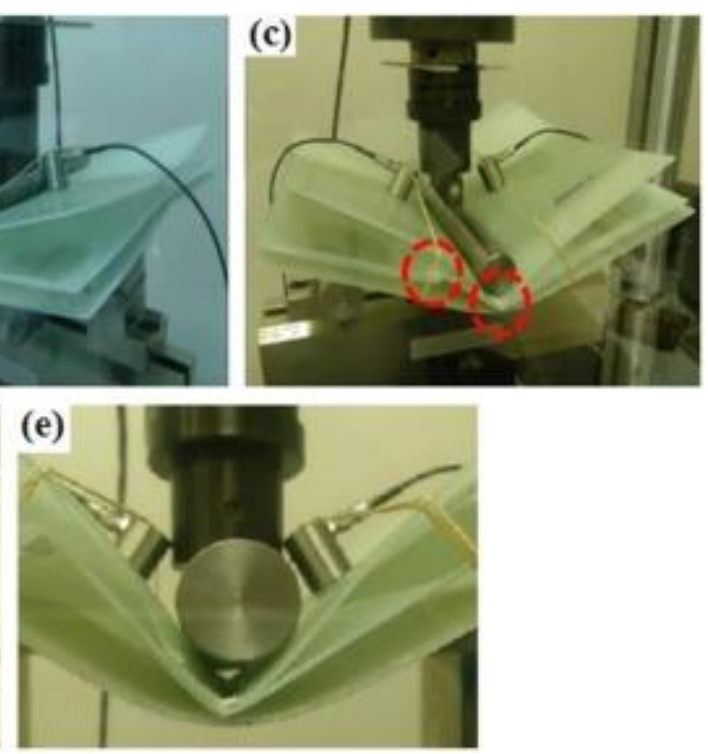

Fig. 10. Three-point bending test depicted at the stage when the deflection of the middle bar is (a) $17 \mathrm{~mm}$, (b) $28 \mathrm{~mm}$, (c) $52 \mathrm{~mm}$ (d) $52 \mathrm{~mm}$, and (e) $66 \mathrm{~mm}$.

Fig. 11 shows the change in the load with the displacement of the middle bar and the corresponding peak frequency of the AE data for specimen 2 and specimen 3. The figure also shows the energy levels and the cumulative counts up to $10 \mathrm{~mm}$ displacement, beyond which energy and the cumulative counts take too high values to show them in the graph. These values are not shown in order to see clearly the signals in the early stages of damage progression, considering that the focus of this study is the initial damage behavior, not post failure behavior. Cumulative counts are scaled to fit the graph. The energy values are not scaled; their absolute values are shown in the secondary axis. 

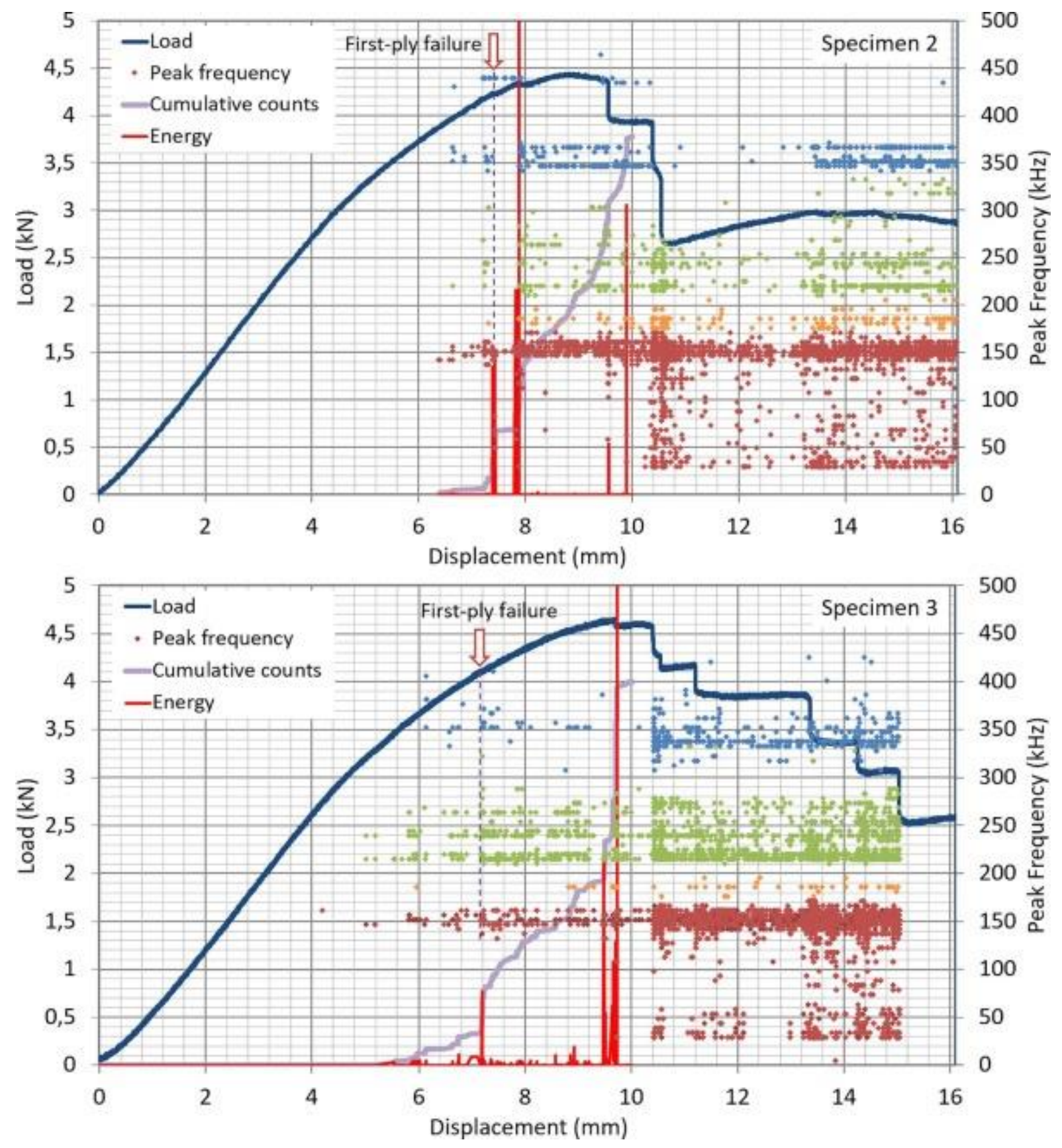

Fig. 11. Peak frequency distribution of $A E$ hits and load vs. displacement for two sandwich specimens under three-point bending, together with energy levels and cumulative counts of the AE hits up to $10 \mathrm{~mm}$ displacement.

In specimen 2, the load-deflection curve is linear up to about $3.0 \mathrm{kN}$; then the slope of the curve continuously decreases until the ultimate load level is reached. The initial decrease in the stiffness can be attributed to geometric nonlinearity due to local buckling of core faces as will be discussed. In the later stages, progressing damage also contributes to degradation in stiffness. AE instrument starts detecting signals at $3.8 \mathrm{kN}$, but with low energy levels. These may be due to micro damage in the material or noises resulting from sliding of $A E$ transducers. At $4240 \mathrm{~N}, \mathrm{AE}$ hits with relative high energy levels are detected; there is a corresponding jump in the cumulative counts and a slight discontinuity in the load-deflection curve. Accordingly, the first-ply failure load is taken to be $4240 \mathrm{~N}$. When the load level reaches $4330 \mathrm{~N}$, signals with very high energy levels are obtained; the density of the frequency bands including $350-370 \mathrm{kHz}$ increases; the load-deflection curve exhibits a 
considerable change in slope. All these indicate that significant damage occurs in the specimen including rupture of fibers. After that the ultimate load is soon reached, beyond which the load carrying capacity of the specimen decreases.

In specimen 3, the load-displacement curve is also linear up to $3.0 \mathrm{kN}$; after that it is nonlinear with reduced stiffness. Below $4.1 \mathrm{kN}$, the $\mathrm{AE}$ signals have low energy levels; therefore, they may be due to micro cracks or noises. Above $4110 \mathrm{~N}$, a hit with a high energy level is detected accompanied by rapid increase of AE signals; correspondingly a jump appears in the cumulative-counts curve. This implies that considerable damage occurs at $4110 \mathrm{~N}$. This is considered as the first-ply failure load. After the ultimate load level is reached, discontinuities in the curve are observed accompanied by high numbers of $A E$ hits with frequencies indicating occurrence of all failures modes. Peak frequencies in 180-200 kHz band, which may indicate delamination, are detected in significant number only after the ultimate load level is reached. After that, the load bearing capacity of the plate decreases; however it can still withstand loads above $2.5 \mathrm{kN}$ until the deflection reaches $18 \mathrm{~mm}$ (Fig. 10a).

In both specimens, a new frequency band around $50 \mathrm{kHz}$ appears after 10.4-mm deflection, following ultimate failure. Each time a large number of $A E$ signals with peak frequencies around $50 \mathrm{kHz}$ are recorded, a sudden drop occurs in the load carrying capacity of the specimens. That is presumed to be due to fracture of the skin or core plates as shown in circles in Fig. 10.

\subsection{Comparison with FEM results - Strength of the plate}

In order to verify the finite element model, the loading conditions up to the peak load level are considered. In order to predict the failure behavior after the plate undergoes substantial damage, a progressive model has to be developed, which is not within the scope of this study. The structural model with rubber bands is subjected to deflection controlled loading by setting the displacement of the middle bar, U3, to $8 \mathrm{~mm}$. The maximum in-plane principal stress state in the top layer of the core and top face sheet are shown in Fig. 12. The fibers are oriented in the $x$ direction. There is stress concentration at the edges of the core, where initial damage is expected to occur. 


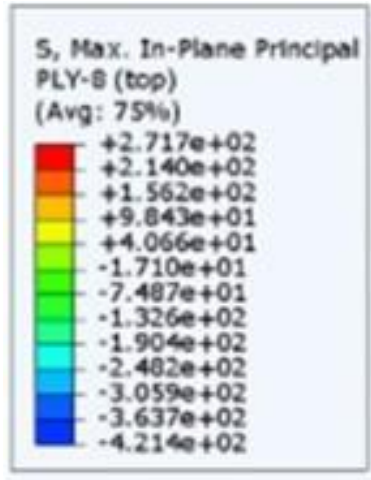

(a)
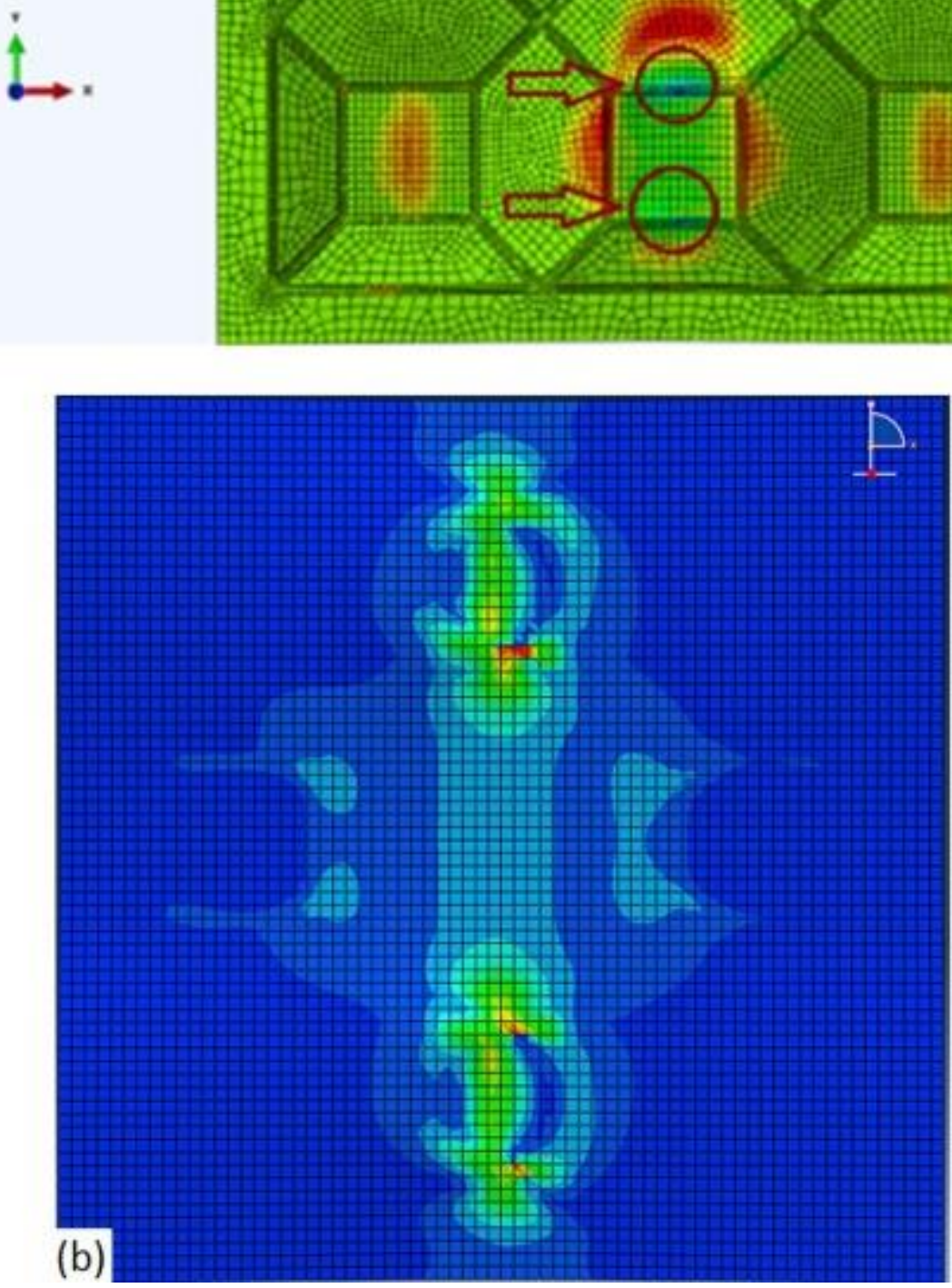

Fig. 12. The maximum in-plane principal stress state distribution in (a) the core and (b) the face sheet corresponding to 8-mm displacement.

Fig. 13 shows Tsai-Hill failure index distribution in the middle layer of the core, where fibers run in the y-direction. Fig. 14 shows the change in the failure index in the critical region as the load is increased. The edges of the core naturally cause stress concentration. In Fig. 13, Fig. 14, 1.0 is 
selected as the upper limit. In the grey regions, the failure index is above 1.0, therefore they are assumed to have failed.

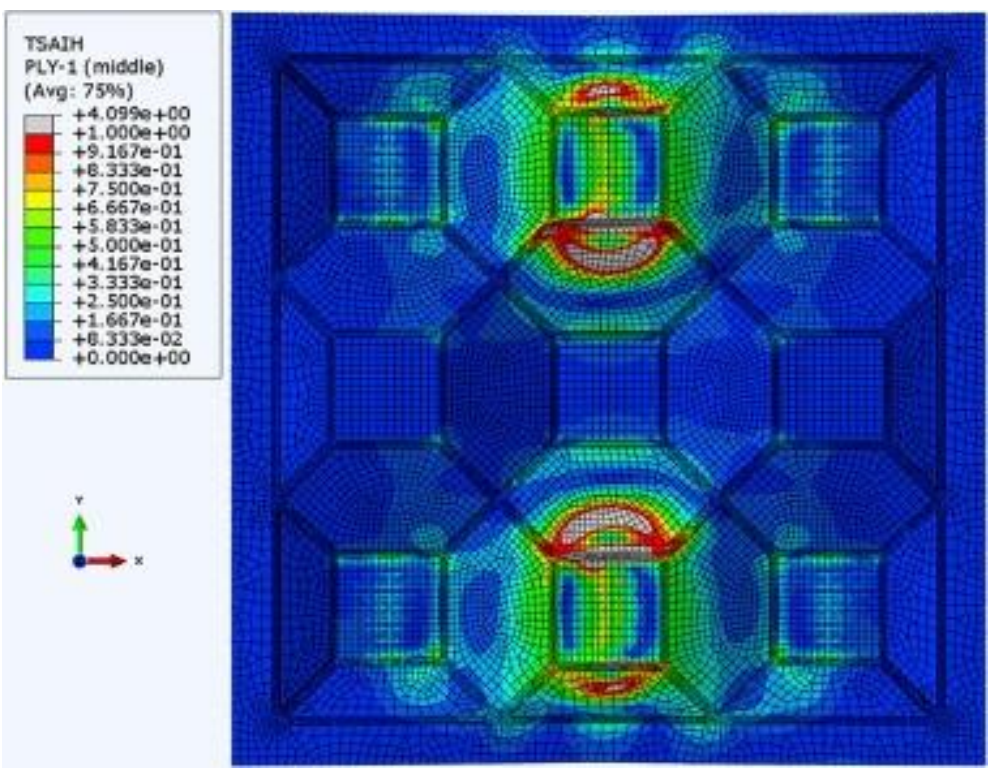

Fig. 13. The failure index distribution of the core.
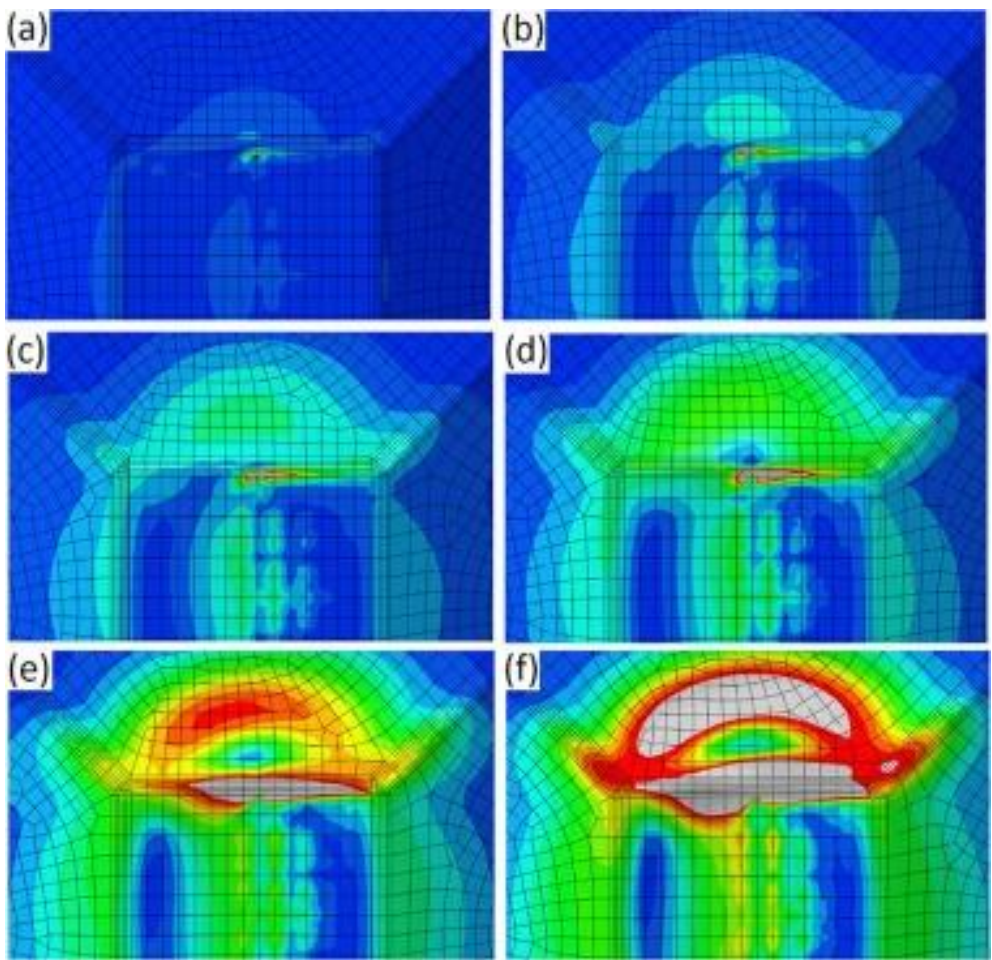

Fig. 14. The failure index distribution for the top layer of the core at when the deflection of the middle bar is (a) $1.6 \mathrm{~mm}$, (b) $3.2 \mathrm{~mm}$, (c) $4 \mathrm{~mm}$, (d) $4.8 \mathrm{~mm}$, (e) $6.4 \mathrm{~mm}$, and (f) $8 \mathrm{~mm}$.

The first specimen is cut into two pieces for inspection (Fig. 15a). Comparing the distribution of the failure index predicted by the FE model in Fig. 14 and the failed regions in the specimen shown in Fig. 15b, one may infer that the agreement between the model predictions and the test results is quite satisfactory. Significant damage occurs at the side walls of the unit cells in the core. 

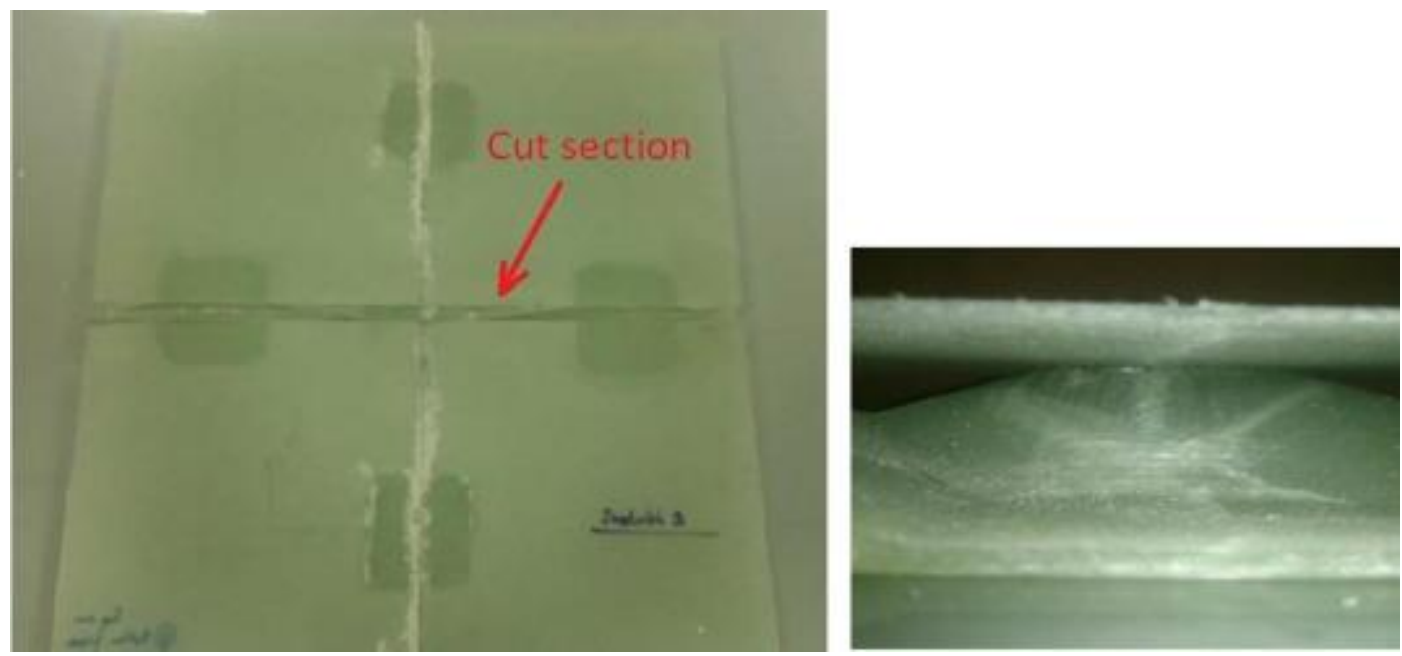

Fig. 15. (a) Specimen 1 cut into two pieces, and (b) damaged region in the core seen through the cut section.

A Python Script code is developed and an iterative study is conducted using Secant algorithm in order to estimate the failure load, at which the maximum failure index is equal to 1.0. If the regions with excessive stress concentration are included in the failure assessment, failure is predicted to occur when the deflection is $1.6 \mathrm{~mm}$ as shown in Fig. 14a; the corresponding reaction force on the middle bar is calculated as $1178 \mathrm{~N}$. In that case, the FE model highly underestimates the failure load. Considering that the top surfaces of the cores are rigidly attached to the face sheets in the FE model, while in reality, the connection is not rigid and the edges of the glued region are not sharp, the predicted stresses in this region are expected to be more severe than the actual stresses both in the face sheet and the core. This is one of the reasons of underestimating the strength. Secondly, initial damage that occurs locally at stress concentration regions hardly affect the macro behavior of the structure. Because of these reasons, the regions with severe stress concentration are neglected in the strength assessment procedure. There are two cells of the core on the $y-z$ symmetry plane which are directly attached to the top face sheet and there are two edges parallel to the $x$-direction for each cell, where stresses are locally high. Between the glued surfaces and the angulated core walls, the curved fillet regions exist. Tsai-Hill failure index values at all the elements on these four fillets and the first rows of the elements at the two sides of these regions are not taken into account. Similarly, the elements of the top face sheet which lie within the vertical projection of the neglected areas of the core are also not taken into account. Along the thickness of a single ply, threeintegration points are defined. Accordingly, there are 24 sections in a single element for the model. Each section has four integration points since S8R is the selected element type. After six iterations, the algorithm finds that the initial failure occurs at the 24th section when the deflection of the middle bar is $6.02 \mathrm{~mm}$. The 24th section is in the top layer of the core. In this layer, the longitudinal fiber direction is perpendicular to the axis of the middle bar. Corresponding reaction force is obtained to be $3961 \mathrm{~N}$. For this loading condition, the distribution of the failure index on the top layer of the core is shown in Fig. 16. As indicated in the figure, the initial failure occurs at an angulated core wall. In the most critical element, where Tsai-Hill failure index is equal to 1.0, the transverse stress is $69 \mathrm{MPa}$, which is equal to the transverse tensile strength of the composite material, while the other stress components in principal material directions are much lower than their respective strengths. Therefore, one may conclude that the predicted first-ply failure mode is matrix failure. The FE model results reveal that tensile stresses develop in the top layer of the core in the critical region shown in Fig. 16, while compressive stresses develop in the bottom layer, which means that the wall of the core buckles outward. This implies that local buckling in the core is one of 
the failure mechanisms. The nonlinearity in the load-displacement curve of the sandwich plate (Fig. 11) may partially be attributed to local buckling beside damage progression. As mentioned before, the first-ply failure loads of specimen 2 and specimen 3 are $4240 \mathrm{~N}$ and $4110 \mathrm{~N}$, respectively (Fig. 11). The predicted failure load is about $5 \%$ lower. The correlation between numerical and empirical results is considered to be satisfactory.

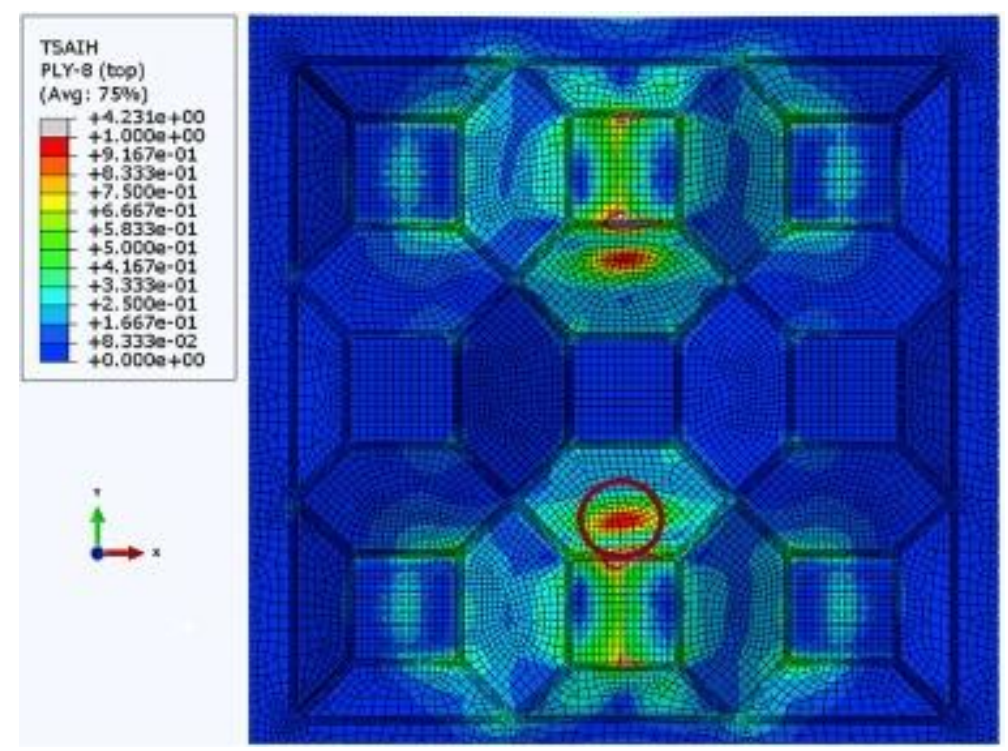

Fig. 16. Tsai-Hill failure index distribution corresponding to the predicted failure load (4590 N) and the initial failure location. Initial failure occurs in the encircled region.

\subsection{Comparison with FEM results - Stiffness of the plate}

Fig. 17 shows the load vs. deflection curve predicted by the FE model and the curve obtained by testing sandwich specimen 1 . In this test (Fig. 4), rubber bands are not used between the bars and the specimen; for this reason the ultimate load is reached with a lower displacement. The agreement between the results of the FE model and the actual mechanical response of the sandwich structure is acceptable. Even though linear material properties are used and progression of damage is not taken into account in the FE model, nonlinear mechanical response of the plate due to local buckling is predicted by the model. The difference between the predicted and measured curves can be explained by a number of factors: First, elastic moduli of the composite material in different directions are not directly measured; but evaluated based on the tension test results of quasiisotropic and cross-ply laminates; for this reason there may be some errors. Secondly, elastic moduli in tension and compression are taken the same; but this may not be the case. Thirdly, the thickness of the core is taken in the FE model the same as the thickness of the face sheets $(1.20 \mathrm{~mm})$; actually it is measured as $1.40 \mathrm{~mm}$. Although, the fiber content is the same and the elastic modulus of the matrix is small, this leads to some error. However, considering the experimental scatter, the error in the predictions is small. Table 6 gives a comparison of the first-ply failure and peak load levels predicted by the FE model and the test results. 


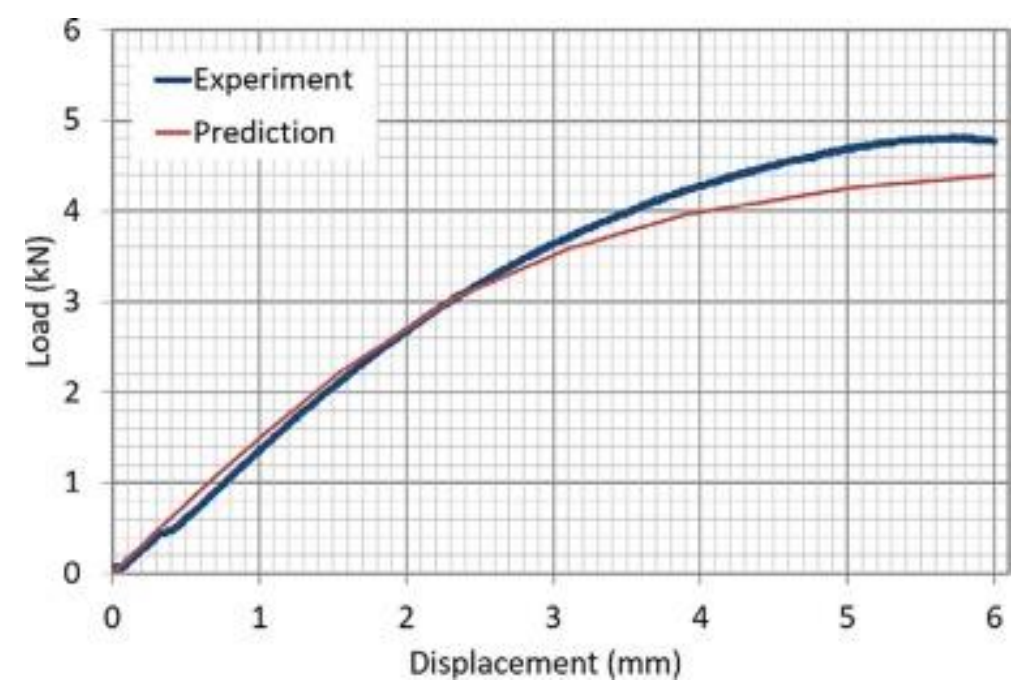

Fig. 17. Comparison of load vs. middle bar deflection curve predicted by the FE model and the one obtained by testing sandwich specimen 1, which does not include rubber bands (Fig. 4).

Table 6. Comparison of the failure load levels predicted by the FE model and the test results for the sandwich specimens.

\begin{tabular}{|l|l|l|}
\hline Test Results & 1st ply failure load [N] & Peak load [N] \\
\hline Specimen 1 & - & 4820 \\
\hline Specimen 2 & 4240 & 4430 \\
\hline Specimen 3 & 4110 & 4650 \\
\hline FEM & 3961 & - \\
\hline
\end{tabular}

\section{Conclusions}

In this study, the failure behavior of a sandwich plate with an egg-crate shaped core design is investigated. The structure is manufactured by vacuum infusion method. The resin used is epoxy and the reinforcement is non-crimp fabric made of E-glass-fibers. In order to understand the failure behavior under out-of-plane loading, the sandwich plates are tested using a three-point bending setup under real-time acoustic emission monitoring. The collected AE data are post-processed and classified according to their dominant frequency characteristics. It is found out that under transverse forces, the sandwich plates can withstand loads up to $5 \mathrm{kN}$; first-ply failure occurs due to local buckling of side walls at about $4.1 \mathrm{kN}$. In the deflection-controlled experiments, beyond the peak load level, the structure is observed to withstand further deformation without catastrophic failure. After some point, extensive fiber failures are observed; still the part can carry $1.8 \mathrm{kN}$ load even after the transverse deflection exceeds three times the plate thickness.

In order to predict the failure behavior of the sandwich plate, a Python Script code is developed to model the structure and simulate three-point bending tests. As the failure measure, Tsai-Hill failure criterion is adopted. The failure load is found iteratively using the secant algorithm and the outcome is compared with the experimental results. The region of failure, mode of failure, and the load level at which failure initiates are predicted within reasonable accuracy. The FE element model can predict the first-ply-failure load level within $5 \%$ error margin.

In this study, a procedure is proposed to determine the strength properties of the laminates reinforced by non-crimp fabrics, using tension test and $A E$ results for specimens with [0/45/-45/90]s 
and [0/90]2s layup sequences and a progressive failure model. Using this procedure, longitudinal and transverse tensile strengths, $\mathrm{Xt}$ and $\mathrm{Yt}$, and shear strength, $\mathrm{S}$, can be obtained.

Structural design optimization of the core and comparison of the new sandwich design with conventional sandwich designs like corrugated and foam filled sandwiches are left as future studies.

\section{Acknowledgment}

This paper is based on the study supported by Bogazici University Research Fund with grant number 11168-16A06P2. The authors would also like to thank to Istanbul Development Agency, which supported the development of the infrastructure of Composites Laboratory in Bogazici University under project code ISTKA/BIL/2012/58.

\section{References}

[1] L.L. Yan, B. Han, B. Yu, C.Q. Chen, Q.C. Zhang, T.J. LuThree-point bending of sandwich beams with aluminum foam-filled corrugated cores

Mater Des, 60 (2014), pp. 510-519

[2] P. NavarroAnalytical modeling of indentation of composite sandwich beam

J Compos Struct, 100 (2013), pp. 79-88

[3] V.S. Deshpande, N.A. FleckCollapse of truss core sandwich beams in 3-point bending

Int J Solids Struct, 35 (2001), pp. 6275-6305

[4] H. Fan, L. Yang, F. Sun, D. FangCompression and bending performances of carbon fiber reinforced lattice-core sandwich composites

Compos A, 52 (2013), pp. 118-125

[5] J. Chung, A.M. WaasCompressive response and failure of circular cell polycarbonate honeycombs under in-plane uniaxial stresses

Trans ASME, 121 (1999), pp. 494-502

[6] J. Chung, A.M. WaasCompressive response of circular cell polycarbonate honeycombs under inplane biaxial static and dynamic loading. Part I: experiments

Int J Impact Eng, 27 (2002), pp. 729-754

[7] I.M. Daniel, E.E. Gdoutos, J.L. Abot, K. WangDeformation and failure of composite sandwich structures

J Thermoplast Compos Mater, 16 (2003), pp. 345-364

[8] J. Kim, S.R. SwansonDesign of sandwich structures for concentrated loading

Compos Struct, 52 (2001), pp. 365-373

[9] J. Kim, S.R. SwansonDesign of sandwich structures under contact loading

Compos Struct, 59 (2003), pp. 403-413

[10] Y. Aminanda, B. Castanie, J.J. Barrau, P. ThevenetExperimental analysis and modeling of the crushing of honeycomb cores 
Appl Compos Mater, 12 (2005), pp. 213-227

[11] V. Vadakke, L.A. CarlsonExperimental investigation of compression failure of sandwich specimens with face/core debond

Compos B, 35 (2004), pp. 583-590

[12] A.R. Othman, D.C. BartonFailure initiation and propagation characteristics of honeycomb sandwich composites

Compos Struct, 85 (2008), pp. 126-138

[13] J. Kim, S.R. SwansonFailure modes and optimization of sandwich structures for load resistance J Compos Mater, 37 (2003), pp. 649-667

[14] T.S. Lim, C.S. Lee, D.G. LeeFailure modes of foam core sandwich beams under static and impact loads

J Compos Mater, 38 (2004), pp. 1639-1662

[15] A. Petras, M.P.F. Sutcliffelndentation failure analysis of sandwich beams

Compos Struct, 50 (2000), pp. 311-318

[16] A. Petras, M.P.F. Sutcliffelndentation resistance of sandwich beams

Compos Struct, 46 (1999), pp. 413-424

[17] M. Giglio, A. Manes, A. Gilliolilnvestigations on sandwich core properties through an experimental-numerical approach

Compos B, 43 (2012), pp. 361-374

[18] T. GeorgeDeshpande VS, and Wadley HNG. Mechanical response of carbon fiber composite sandwich panels with pyramidal truss cores

Compos A, 47 (2013), pp. 31-40

[19] L. Aktay, A.F. Johnson, B.H. KröplinNumerical modelling of honeycomb core crush behaviour

Eng Fract Mech, 75 (2008), pp. 2616-2630

[20] R.A. Staal, G.D. Mallinson, K. Jayaraman, D.P.W. HorriganPredicting failure loads of undamaged sandwich honeycomb panels subject to bending

J Sandwich Struct Mater, 11 (2009), pp. 73-104

[21] R. Brooks, K.A. Brown, N.A. Warrior, P.P. KulandaivelPredictive modeling of the impact response of thermoplastic composite sandwich structures

J Sandwich Struct Mater, 12 (2010), pp. 449-476

[22] G. ReyesStatic and low velocity impact behavior of composite sandwich panels with an aluminum foam core

J Compos Mater, 42 (2008), pp. 1659-1670

[23] D. Zenkert, A. Shipsha, K. PerssonStatic indentation and unloading response of sandwich beams 
Compos B, 35 (2004), pp. 511-522

[24] M. Li, L. Wu, L. Ma, B. Wang, Z. GuanStructural response of all-composite pyramidal truss core sandwich columns in end compression

Compos Struct, 93 (2011), pp. 1964-1972

[25] V. Crupi, G. Epasto, E. GuglielminoCollapse modes in aluminium honeycomb sandwich panels under bending and impact loading

Int J Impact Eng, 43 (2012), pp. 6-15

[26] E.E. Gdoutos, I.M. Daniel, K.A. Wang, J.L. AbotNonlinear behavior of composite sandwich beams in three-point bending

Exp Mech, 41 (2001), pp. 182-189

[27] M. Mohamed, S. Anandan, Z. Huo, V. Birman, J. Volz, K. ChandrashekharaManufacturing and characterization of polyurethane based sandwich composite structures

Compos Struct, 123 (2015), pp. 169-179

[28] A.C. Manalo, T. Aravinthan, W. Karunasena, M.M. IslamFlexural behaviour of structural fibre composite sandwich beams in flatwise and edgewise positions

Compos Struct, 92 (4) (2010), pp. 984-995

[29] M.R.M. Rejab, W.J. CantwellThe mechanical behavior of corrugated-core sandwich panels

Compos B, 47 (2013), pp. 267-277

[30] L. Aktay, A.F. Johnson, M. HolzapfelPrediction of impact damage on sandwich composite panels Comput Mater Sci, 32 (2005), pp. 252-260

[31] J. Romanoff, P. VarstaBending response of web-core sandwich plates

Compos Struct, 81 (2007), pp. 292-302

[32] R.C. ØstergaardBuckling driven debonding in sandwich columns

Int J Solids Struct, 45 (2008), pp. 1264-1282

[33] Y. FrostigBuckling of sandwich panels with a flexible core-high-order theory

Int J Solids Struct, 35 (1998), pp. 183-204

[34] P. Qiao, M. YangImpact analysis of fiber reinforced polymer honeycomb composite sandwich beams

Compos B, 38 (2007), pp. 739-750

[35] T.C. Lin, T.J. Chen, J.S. HuangIn-plane elastic constants and strengths of circular cell honeycombs Compos Sci Technol, 72 (2012), pp. 1380-1386

[36] C.F. Caner, Z.P. BazantSize effect on strength of laminate-foam sandwich plates: finite element analysis with interface fracture 
Compos B, 40 (2009), pp. 337-348

[37] G. Guinta, A. Catapano, S. BelouettarFailure indentation analysis of composite sandwich plates via hierarchical models

J Sandwich Struct Mater, 15 (2012), pp. 45-70

[38] E.E. Gdoutos, I.M. DanielFailure modes of composite sandwich beams

J Theor Appl Mech, 35 (2008), pp. 105-118

[39] N. Wicks, J.W. HutchinsonPerformance of sandwich plates with truss cores

Mech Mater, 36 (2004), pp. 739-751

[40] Wadim JR. Acoustic emission applications. Dunegan Endevco, San Juan Capistrano, CA; 1978.

[41] V. Aramugam, S.B. Kumar, C. Santulli, A.J. StanleyEffect of fiber orientation in uni-directional glass epoxy laminate using acoustic emission monitoring

Acta Metall Sin, 24 (2011), pp. 351-364

[42] J. Arumugam, C.S. Kumar, C. Santulli, F. Sarasini, A.J. StanleyA global method for the identification of failure modes in fiberglass using acoustic emission

J Test Eval, 39 (5) (2011)

[43] A. Bussiba, M. Kupiec, S. Ifergane, R. Piat, T. BöhlkeDamage evolution and fracture events sequence in various composites by acoustic emission technique

Compos Sci Technol, 68 (2008), pp. 1144-1145

[44] R. Asokan, V. Aramugam, C. Santulli, et al.Investigation of the strength of the failure modes in gfrp laminates using acoustic emission monitoring

J Reinf Plast Compos, 31 (2012), pp. 1226-1235

[45] P.J. Groot, P.A.M. Wijnen, R.B.P. JanssenReal-time frequency determination of acoustic emission for different fracture mechanisms in carbon/epoxy composites

Compos Sci Technol, 55 (1995), pp. 405-412

[46] M. Fotouhi, P.B. Dastjerdi, M. AhmadiAcoustic emission based method to characterize glass/epoxy composite damages during 3-point bending test

Int J Mater Sci, 4 (1) (2014)

[47] E. Segard, S. Benmedakhene, A. Laksimi, D. LaiDamage analysis and the fibre-matrix effect in polypropylene reinforced by short glass fibres above glass transition temperature

Compos Struct, 60 (2003), pp. 67-72

[48] R. Gutkin, C.J. Green, S. Vangrattanachai, S.T. Pinho, P. Robinson, P.T. CurtisOn acoustic emission for failure investigation in CFRP: pattern recognition and peak frequency analyses

Mech Syst Signal Process, 25 (4) (2011), pp. 1393-1407 
[49] L. Li, S.V. Lomov, X. Yan, V. CarvelliCluster analysis of acoustic emission signals for 2D and 3D woven glass/epoxy composites

Compos Struct, 116 (1) (2014), pp. 286-299

[50] L. Li, S.V. Lomov, X. YanCorrelation of acoustic emission with optically observed damage in a glass/epoxy woven laminate under tensile loading

Compos Struct, 123 (2015), pp. 45-53

[51] S.E. Mechraoui, A. Laksimi, S. BenmedakheneReliability of damage mechanism localisation by acoustic emission on glass/epoxy composite material plate

Compos Struct, 94 (2012), pp. 1483-1494

[52] F.E. Oz, N. Ersoy, S.V. LomovDo high frequency acoustic emission events always represent fibre failure in CFRP laminates?

Compos Part A Appl Sci Manuf, 103 (2017), pp. 230-235

[53] Oz FE, Ersoy N, Mehdikhani M, Lomov SV. Multi instrument in-situ damage monitoring in quasiisotropic CFRP laminates under tension. Submitted to Compos Struct. (under revision).

[54] HEXION ${ }^{\circledR}$ Specialty Chemicals, Laminating Resin MGS ${ }^{\circledR}$ L 285 Hardeners MGS ${ }^{\circledR}$ 285-287 Technical Data Sheet, http://www.hexion.com/products/technicaldatasheet.aspx?id=30303, last accessed September 2016.

[56] METYX Composites Company - Reinforcements Technical Datasheets.

[57] AEWin SoftwareUser's reference manual, Rev. 4.

MISTRAS Group Inc., Products \& Systems Division, Princeton Junction, NJ, USA (2011)

[58] G.A. Bibo, P.J. Hogg, M. KempMechanical characterisation of glass- and carbon-fibre-reinforced composites made with non-crimp fabrics

Compos Sci Technol, 57 (9-10) (1997), pp. 1221-1241

[59] S. Laustsen, E. Lund, L. Kühlmeier, O.T. ThomsenInterfibre failure characterisation of unidirectional and triax glass fibre non-crimp fabric reinforced epoxy laminates

Appl Compos Mater, 22 (1) (2014), pp. 51-79

[60] Abaqus Theory Guide, ABAQUS Inc, Version 6.14., USA; 2017.

Further reading

[55] R.F. GibsonPrinciples of composite materials mechanics

Taylor \& Francis (2012) 